Portland State University

PDXScholar

$1-1-2010$

\title{
The Pulpit at the End of the Rainbow: How Queer Clergy Enter Into and Maintain Religious Occupations
}

Brian Gregory Gerow

Portland State University

Follow this and additional works at: https://pdxscholar.library.pdx.edu/open_access_etds Let us know how access to this document benefits you.

\section{Recommended Citation}

Gerow, Brian Gregory, "The Pulpit at the End of the Rainbow: How Queer Clergy Enter Into and Maintain Religious Occupations" (2010). Dissertations and Theses. Paper 39.

https://doi.org/10.15760/etd.39

This Thesis is brought to you for free and open access. It has been accepted for inclusion in Dissertations and Theses by an authorized administrator of PDXScholar. Please contact us if we can make this document more accessible: pdxscholar@pdx.edu. 
The Pulpit at the End of the Rainbow:

How Queer Clergy Enter Into and Maintain Religious Occupations

\author{
by \\ Brian Gregory Gerow
}

A thesis submitted in partial fulfillment of the requirements for the degree of

\author{
Master or Arts \\ in \\ Sociology \\ Thesis Committee: \\ Lindsey Wilkinson, Chair \\ Ann Mussey \\ Daniel Sullivan \\ Portland State University \\ (C)2010
}


TABLE OF CONTENTS

CHAPTER 1: Introduction

-Introduction

-Research Questions

-Key Terms

CHAPTER 2: Review of Literature \& Relevant Theory

-Changes in Ordination

- Stigma Theories \& Destigmatized Space

-Tokenism

-Role Theory

-Identity Theory

CHAPTER 3: Methods

-Participant Recruitment

-Interview Guide

Analysis and Coding

CHAPTER 4: Findings

-God's Calling

-Childhood \& Young Adult Influences

-Seminary

-Political Activism

-Denominational Policies and Practices

-Homophobia (Internal \& External)

CHAPTER 5: Discussion

-God's Calling

-Childhood \& Young Adult Influences

-Seminary

-Political Activism

-Denominational Policies and Practices

-Homophobia (Internal \& External)

CHAPTER 6: Future research \& Conclusion

APENDIX A: Demographics

APPENDIX B: Interview Guide Sample

APPENDIX C: Interview Consent Letter 


\section{CHAPTER 1: INTRODUCTION}

"Thou shalt not lie with mankind as with womankind: It is an abomination" (Leviticus 18:22). Biblical claims such as this have been used by opponents of same sex sexuality for many years, in an effort to maintain a status quo that subjugates sexual and gender minorities. This inquiry was conducted in direct opposition to this and similar negative views of people who identify as queer, or identify anywhere within the GLBTQQI (etcetera) spectrum. The purpose of this in-depth interview study is to explore the factors that encourage or discourage queer clergy to enter their traditionally heteronormative occupations. All of these interviews were conducted in and around Portland, Oregon. Queer clergy are a recently formed and growing population in many religious communities, and Portland has been pinpointed by several religious leaders as an exceptionally progressive city, where groups of otherwise outcast minorities can actively create change in traditionally hetero-masculine/heteronormative cultures, such as Christian churches. Furthermore, this research will add to the very limited scientific exploration into the experience of queer identified religious leaders.

Although the number of occupational positions for queer clergy is growing, and more churches are opening their doors to gender and sexual minorities, the number of queer identified people who do not manage to complete the process of ordination is still much greater than of those who do (Wilcox 2003). While this study focuses on queer identified people who have managed to complete the process of ordination and is unable to directly address why queer identified people do not complete the process, this study will shed light on obstacles that queer identified clergy face on the path to ordination. Numerous works on identity and role theory have made it clear that the more a person is 
surrounded by others who affirm their identity, the more likely that person is to maintain their role. If a queer clergy member is a member of a congregation attended by other queer Christians, and their friends outside their church have a positive perception of their clergy role, they may be much more likely to pursue and maintain that role. The influence of positive others in the entrance into and maintenance of queer clergy positions may be particularly relevant in Portland, a city that has become know for being progressive and accepting of sexual minorities. Thus, this study will use identity theories to understand the entrance into and maintenance of clergy positions among queer identified individuals living and working in Portland, Oregon. Furthermore, Callero's role theory suggests that being "out," publically, must benefit people in some way. Because all of the ministers in this study are out to all groups in their lives, role theories may help to explain how using one's role as a resource contributes to the entrance into and maintenance of clergy positions among queer identified individuals.

\section{Study's Significance}

From the perspective of identity and role theories I hope to obtain a better understanding of what factors influence a minister's choice to become a clergy member, and what factors bolster that decision. Much of social identity theory would suggest that a person requires a strong and supportive community in order to succeed, accompanied by minimal oppositional personalities within those communities. Gaining insight into the ways a queer clergy member's communities are formed and understood by each clergy member will help assess the relevance of identity theories in understanding how queer 
individuals enter into and maintain clergy positions (Stryker 2000). The role a queer clergy member holds as their master status may also affect their place in heteronormative religious culture and how they overcome the stigma often associated with same-sex sexuality in Christian churches. Theories of how the importance of roles can shift and concepts such as tokenism and sexual stigma, which suggest how roles are affected by their existence in a traditionally heteronormative space, will be a crucial element to assess throughout this research process. Identity and role conflicts have had a great deal of influence on the lives of queer people in other helping occupations, for example teachers and police officers. An assessment of the similarities and differences between these occupations will be useful to gain understanding of the way ministers enter and endure a traditionally heteronormative occupation.

This inquiry is also significant in regards to increasing knowledge about possible biases within religious culture toward queer clergy that impact their entrance into a traditionally heteronormative occupation. Polity and congregants who interact with queer clergy, as well as other institutions involved in their personal and occupational lives, should also gain from the information gathered by this research. A greater understanding of the meaning of clergy positions, held by out queer identified persons, might help ministers become more aware of the range of each minister's personal understandings and emotional commitments, as well as the types and extent of their involvement in religious culture. This research might also provide information about the range of opportunities in clergy positions for queer Christians, who might otherwise abstain from becoming involved due to traditional aspects and beliefs of some religious institutions. 
Finally, illuminating the lived experiences and personal narratives of religious leaders may serve to inspire involvement by others in the queer movement, as well as those who have not currently made their sexual or gender identities public knowledge. With the findings of this research I have attempted to create a space where clergy members may provide validation for queer clergy who are not only unsure if they have a place in their religious culture, but also what they can offer and what they might hope to gain. Ministers are in positions of authority within their denominations, and all have bodies of governance above them that effect their position. The relationship between clergy and their polity, as it relates to their ordination, will be discussed throughout this document. 


\section{Research Questions}

This research was guided by the following two research questions.

1. What factors encourage or discourage queer identified clergy to pursue a career as professional religious leaders in a traditionally heteronormative occupation? (referred to throughout this document as entrance).

2. What factors encourage or discourage queer identified clergy to maintain their positions as professional religious leaders? (Referred to throughout this document as endurance)

These were selected as two research questions that best fit the highly exploratory nature of this project. These basic questions are necessary, due to the severe lack of literature and research within this culture (or that of any similar phenomena). 


\section{Key Terms}

There are several frequently used terms that need to be defined according to their specific usage in this document. Some of these terms are particular to this research topic, while others are germane to social sciences, theology, and philosophy.

The first of these is the colloquial term "out", which herein is intended to denote persons who publically identify as sexual or gendered minorities, rather than keeping this identity private or secret. This definition is important because a great number of ethical issues could arise if I were to interview people who's minority gender and/or sexual identities were not known by their employers, families or congregations.

The term "queer", for the purposes of this study, is used as an all encompassing (or umbrella) term for non-normative sexual and/or gender identities. These identities could include (but are in no way limited to) lesbian, gay, bisexual, transgender, transsexual, queer, questioning, intersex, and myriad other identity categories, as well as those that do not fit any predetermined category (Quinlivan, Town 1999). Many of the faith traditions related to the people I have interviewed (with the exception of one Wiccan priestess, one Gnostic Priest and one Unitarian Universalist minister) are rooted in conventionally heteronormative, patriarchal faith traditions. As defined by Michel Foucault, "Heteronormativity involves the celebration of heterosexual relationships as well as the organization of culture, including institutions, around such relationships" (Foucault 1978). These include Episcopalian, Methodist, United Church of Christ denominations. Based on this hegemonic heternormative majority, the term queer will include any non heterosexual sexual identity that a clergy member indicates, as well as 
any gender identity that is not attached to that person's biological sex, which is based on a binary (male or female) identity categorization. I am in no way implying that heterosexual individuals cannot identify as queer (and many do), but simply that those who directly identify as heterosexual are making a claim that they are part of an accepted and privileged identity. I will provide a more in depth depiction of queer identity in the following sections.

Clergy herein refers to leaders of churches and denominations in various religious institutions. Several clergy referred to their position as the "professionally Christian". The term minister or reverend will also be used, interchangeably, for many of these same people. Some traditions have their own designated nomenclature for clergy, for example the term priest in the MCC, and these clergy will be designated accordingly.

Denomination and faith tradition are used interchangeably throughout my research writing, and are both defined the same way. There are innumerable definitions of denomination and faith traditions, but for the purposes of this research I chose a traditional institutionally focused definition beginning with social theorist Emile Durkheim's definition of religion. "A religion is a unified system of beliefs and practices relative to sacred things, that is to say, things set apart and forbidden and practices which unite into one single moral community called a Church, all those who adhere to them" (Durkheim 1912). Hence, religion is the overarching umbrella (Berger 1990) under which faith traditions have been created as different ways of interpreting and organizing that religion. With this and similar definitions for the underlying understanding of religion as a basis for faith traditions and denominations, I will essentially conflate these two terms. 
There are many other terms and concepts that will need to be defined which were used less frequently than these, and they will be outlined within the text they pertain to.

This thesis is divided into six chapters. Chapter 1 introduces the main research questions and includes brief overview of terms used within this document. Chapter 2 discusses the literature reviewed that helped to inform this research project, along with discussing the theoretical motivations and frameworks that emerged from the transcripts. Chapter 3 will exhibit the methodological procedures used to collect and analyze the interview data. First, a discussion of the particular interview methodology used for this study will be given, followed by a discussion of analysis of the transcriptions and potential biases. Chapter 4 reveals the findings of this study for all phases of the research. Chapter 5 is a discussion of some of the key findings from this study as well as recommendations for future research and some methodological aspects to consider while performing research around gender and sexualities. Lastly, Chapter 6 will provide a summary of the study as well as concluding thoughts. 


\section{CHAPTER 2: Review of Relevant Literature \& Theory}

In this chapter I will briefly review the history of traditional Christian clergy positions as they opened up to women's' ordination, trailed less than a decade later by the ordination of sexual and gender minorities. Historical context will illuminate how some religious institutions moved from persecuting to ordaining women and queer Christians, over a period of roughly twenty years. I will follow this with a discussion of the theoretical contexts useful in this study: stigma, identity theory, and role theory. Lastly, I will review the limited literature on queer clergy and some additional literature on sexual and gender minorities in similar helping occupations. These theoretical essays and research articles will direct this research project toward some conclusions concerning ministers' entrance and endurance in their occupation.

\section{Changes in Ordination}

To begin it is necessary to understand that the meanings and consequence of sexuality, sexual behavior, and sexual identity have shifted over time, in both religious and secular cultures. For example, prior to the era of Roman rule, there were several cultures (including but not limited to ancient Greece) that not only condoned same sex sexual behavior between men, but upheld these behaviors and relationships as rites of passage to adulthood (D'Emilio, Freedman 1988). Women in this same era were often thought to have no desire or sense of sexual pleasure, and were ideologically relegated to the sole sexual role or berthing children. Therefore, women's sexual acts outside childbearing have gone largely unnoticed, unmentioned, and undocumented throughout 
history (Adam 1995).

These and many other understandings and emphases of sexuality have been affected by religions of the culture they existed in, often as much as they affected the religious doctrines and tenets of those same cultures (Boswell 1980). Although contested, it is thought that the first perception of 'homosexuality' as a deviant or punishable act was in sixth century Rome (Boswell 1980: 71). However, "It is virtually impossible to speak with authority on Roman prejudices, since they so often occur in satirical or ironical contexts" (Boswell 1980: 74). There is no definitive record of precisely when same-sex sexuality first became a punishable behavior, or stigmatized set of actions and emotions that people were hiding from the public. As historian Bary D. Adam wrote, "are the terms we employ in discussing homosexuality - gay, lesbian, homosexual itself (emphasis theirs)- and the meanings we attach to them so much a product of modern western thought that meaningful comparisons, let alone a sense of continuity, are chancy at best, all but impossible at worst?" (Adam 2003: 3).

However, it was at this juncture in Rome when the Catholic Church began to take power over the empire, spread its influence throughout Western Europe, and classify certain social and personal behaviors as deviant, and thus a negative perception of same-sex sexuality is thought to have begun. It was not until empires of the late $13^{\text {th }}$ and $14^{\text {th }}$ centuries, such as that of the Romans, attempted to usurp the power of other nations and single out minorities and subcultures in order to conquer them that homosexuals along with Jewish people, Islamic people and many others were subjugated and persecuted (D'Emilio, Freedman 1988).

The chronology of same sex behaviors and identities of clergy followed a similar 
pattern. Catholic churches, along with Protestant faiths (following the enlightenment), began to eliminate homosexuals from their clergy ranks, as well as expelling congregants from their worship services for suspicion of homosexual acts or tendencies (Boswell 1980). This element of dominant empires is thought to have had the largest effect throughout history on the creation of today's perceptions of same-sex sexuality in religious institutions. Stated plainly, conquering nations demonized people who did not fit their vision of a proper citizen, and drove them away from any possibility of respect or power (Boswell, 1980). These sentiments remained in most Christian traditions until the early 1960's when movements for civil rights and social rights began to emerge in the U.S. and Western Europe.

Thanks in large part to the women's movement of the 1960s some faith traditions have abandoned this negative stance toward same-sex sexual behaviors, and what are now understood as sexual identities, in favor of a more neutral or encouraging stance. "The first woman formally ordained to the Christian ministry in a major Protestant denomination in America was Antoinette L. Brown. She was ordained by the Congregationalists in a small church in upstate New York in 1953" (Zikmund et al 1998: 9). From this point forward, a slow procession toward women's ordination turned to a floodgate opening in the late 1970s, with many denominations agreeing to offer women positions as ministers. Tied closely to the movement for women's ordination was the push for gay and lesbian ordination in Protestant denominations.

It is important to note that barriers to ordination, which this movement was fighting to eradicate, only existed for people who were out. "Out" is a term used to 
denote that one has made their sexual or gender identity public knowledge (not necessarily to everyone, but to people other than themselves). Some denominations were known to ordain people who were not partnered. These institutions only perceived sexuality as a behavior, and when that behavior was not acted upon the person was not perceived as a sexual deviant. It has of course always been possible for closeted clergy to maintain their positions, so long as they never revealed their sexual pleasures, desires, activities, or identities (Hazel 2000).

It is unknown precisely when the first queer minister was ordained, however Gene Robinson is certainly a central figure who many sexual and gendered minorities look to as a source of encouragement and motivation. In 1973, at age 26, Robinson was ordained by the Episcopalian Church. He came out to his wife, and later his congregants and denomination in the mid 1980s. Robinson has since been remarried, was elected Bishop of New Hampshire, and gave the opening prayer at President Obama's inauguration celebration in 2009 (http://www.nhepiscopal.org/). Beginning in the early 1970s gay and lesbians were able to seek ordination in several faiths including: Episcopalian, United Church of Christ, Metropolitan Church of Christ, Unitarian Universalists, among several other progressive faiths. These churches were directly active in the de-stigmatization of queer clergy and congregants, and continue to work toward their goals of equality today.

A basic understanding of the history of ordination and perceptions of Christians who did not fit within the straight male norm for ordained persons is essential to this story of how those perceptions have changed over time. The formation of open and affirming congregations, across the globe, has only been made possible through the fight 
of other movements for civil rights and social justice throughout history. Each successive movement has been informed by the prior movement's successes, and owes part of its success to those prior. As I will discuss in the following findings section, social and political movements have been a key encouragement factor for many clergy members, and the ways these movements have grown and changed are pertinent to understanding the context of those ministers' experiences. It is necessary to have a basic understanding of historical shifts in ordination in order to consider the entrance and endurance barriers and influences clergy encounter today.

\section{Stigma Theories \& Destigmatized Space}

Although stigma surrounding queer people is slowly waning in the U.S., it has in no way vanished. At the outset, there is a stigma in Protestant culture toward queer people that limits their ability to enter and maintain jobs as professional religious leaders. This stigma is generated and perpetuated in the larger secular culture in the west, and is a direct cause of internalized homophobia for gender and sexual minorities.

From the time American children are very young, they are socialized with the anithomosexual biases that are sanctioned by western culture. Upon realizing that they are different from the social norms, and are negatively regarded by society, lesbians, gay men, and bisexuals incorporate these negative feelings into their self image, which results in internalized homophobia. Internalized homophobia can range from self doubt to self hatred (Herek 1998, ch7: 147).

It is this stigma that helped generate both of the research questions for this project: why would clergy enter this occupation in a culture that traditionally places a negative stigma on their sexual or gendered identity, and what are some factors that help them maintain that position despite stigma. As defined by sociologist Erving Goffman, stigma is "an 
attribute that is deeply discredited" (Goffman 1963: 4) in an individual. This attribute (or multiplicity of attributes) shifts the way others perceive that person as a whole being, capable of the same tasks and cognitive functions as themselves, to someone less capable or competent and therefore inferior. The perceived inferiority created through stigma changes the way people interact with the stigmatized individual, and as a result affects the ways in which individuals can interact with others. Stigma also affects the way individuals understand themselves, and thus affects the ways they navigate their social lives. Many queer clergy exist in heteronormative religious institutions, and the stigmas attached to their identities have real lasting effects on those identities and on their lives. For sexual minorities in Christianity, sexuality is often thought of as an ascribed master status, the status that is seen first and foremost by peers and lay persons. Ascribed statuses are those related to characteristics of a person's birth or origin, such as ethnicity and gender, and are not those achieved by an individual, such as socio-economic status or level of education (Macionis 2006). Master status is simply the status that others first recognize a person by, or the status they first recognize themselves by. There exists a highly contested debate over whether the origins of sexuality are biological or social, and I have decided to save my understanding of that inquiry as it is not directly assessed by my research questions. Regardless of the identity a clergy member feels is most important to them, it is often the stigmatized sexual identity that they are recognized by others as. For example, clergy members might think of themselves as a Christian or a caretaker first and foremost, but the way they are perceived and treated by their peers and colleagues might be as a queer person first and foremost. As mentioned previously, the external 
stigma attached to a certain status, which is known to others, may override any internal identities a person holds. These stigmas can have long lasting detrimental effects on a person's life, and often create barriers to accessing resources such as clergy occupations.

\section{Tokenism}

Several researchers have noted that the negative stigma attached to the sexual identity of their participants also creates a sort of tokenism for their role. Tokenism is often seen as a negative phenomenon, wherein people are not seen for who they are, but are relegated as mere examples or scapegoats. Many of the queer ministers I worked with mentioned feeling that they had been singled out in their denominations as spokespersons for all minority members, and it was assumed that they could speak for everyone based on their own minority status. In Edward Lehman's research on clergy women, he found that women in denominations were often upheld as the one shining example of the denomination's quest for equality (Lehman 1995). These women were not paid as well as men, and many of the traditional patriarchal tenets of the denominations they worked for were upheld throughout their careers (Lehman 1995). Similar findings have been written in research with queer college professors, police officers and people in other helping professions as well.

Tokenism can occasionally work in more positive ways, by giving the token person the ability to exist in a position of encouragement for others in their culture, as well as a counselor to those who need reassurance. In their work with queer police officers, Susan Miller and several other researchers noted a very positive effect of tokenism within the ranks of the police force. Having officers who identify with any 
sexual or gender minority status on the force provided the community with mentors who could speak of the experience of some of the civilians they were working with in a much more direct and sensitive manor. This would, of course, include those specific officers working with queer community members on safety issues within their neighborhoods. In large metropolitan areas employing queer officers has been seen as an asset. In fact, something called a GLUU (Gay and Lesbian Unit) has emerged to specifically work with sexual minority safety and offense cases (Tobler 2006). Is there something special about being queer and a minister that enables the participants of my study to better serve their communities, and has this sense of service helped or hindered their entrance into the occupation?

Along with that of police officers, research on sexual and gender minorities in other helping occupations has discussed the barriers people face in entering heternormative spaces. College is also a traditionally heteronormative space. Queer teachers and students are navigating a culture that is predominantly heterosexual and battle the ideologies that result from that culture. In his research on coming out in college, Robert Roads addresses the ways people make a queer safe space in heteronormative culture, and how the cultural borders that are upheld by stigmas are deconstructed and reconstructed. Clergy have had to conduct similar border reconstruction within their religious cultures, creating spaces within the culture that feels safe for gender and sexual minorities to gather, learn, and worship.

The Metropolitan Community Church (MCC) is a clear example of this creation of space. Started by Reverend Troy Perry in 1968, the MCC has a clear mission to 
conduct and create positive ministry for all sexual, gender, and other minorities. "In the early 1960s, Rev. Perry was defrocked as a clergyperson by a Pentecostal denomination because of his homosexuality. He spent the next several years struggling to reconcile his sexuality and his Christian spirituality" (http://ufmcc.com/overview/history-of-mcc/). Later, in his living room in Los Angeles, California MCC was born, and today boasts 43,000 members, in 300 congregations, in 22 countries. Small denominations, of a similar focus, have sprung up since the 1960 s, but he MCC is the only one that has grown to its level of attendance and prestige.

The much more common means of creating space in churches and denominations today is for the church to become an "open and affirming" congregation through an organization like the Community of Welcoming Congregations (CWC). These organizations act as advocates for all gender and sexual minorities in all of their member congregations. The organization also allocates yearly member congregation dues to work on state and federal issues, such as gay marriage legislation, as well as providing education to its members regarding diversity and equality training http://www.welcomingcongregations.org/joincwc.html. The CWC and the Metropolitan Community Church are clear examples of people taking action toward the creation of space for queer clergy and congregants. How has the creation of this specific space helped queer identified clergy find and maintain their occupation?

\section{Role Theories}

The role clergy play in their congregations, and in their denominations, is often 
held in a place of high moral judgment. The vast majority of religious institutions have a set of moral codes that guide followers in their spiritual lives (Linneman 2003). Arbiters of these moral codes are clergy members, who congregants or denominations have appointed to ensure that these morals are properly conveyed and abided by. Why then would a clergy member want to come out to their religious institution and community that may be morally opposed to their sexual or gender identity? Is there an advantage to coming out for religious leaders, and how might this perceived advantage affect their ability or desire to enter the occupation? Whether a clergy member comes out before or after seminary (and ordination for that matter) plays a large role in how difficult it is for them to enter and maintain their occupation (Linneman 2003).

To look at the first of these questions of coming out, Peter Callero's theory of Role as Resource is highly applicable. Clergy members are not forced to come out, but do so for a reason, and, as Callero would have it, that reason likely benefits their lives or the lives of others in some way. An example of this was presented earlier, concerning police officer's and teacher's desires to come out in their occupations in order to be a means of support for others (Rhoads). Relating to identity, roles are most commonly used to define the self and the other. On this, Callero wrote, "When roles are used as a resource to define self and other, I believe it is conceptually appropriate to refer to such roles as identities. Yet roles as resources are not synonymous with identities because they have other, nonidentity uses and are available as cultural objects independent of one's personal identity claim" (Callero 1994: 239). Another way to think about this difference between role and identity is that roles are relevant and exist regardless of whether an individual fills them 
or not, whereas identities only apply to an individual when they attach themselves (or are attached by others) to those identities. It is conceivable that by coming out any person who identifies with a sexual or gendered minority group is choosing to make their minority status political; in turn, this role may be a resource to them. The reasons for revealing gendered and sexual identity to others is not as obvious nor agreed upon as it may appear. Clergy members come out and are out to their congregations for a variety of reasons, and the time that this coming out occurs is often crucial as well. How does this decision to come out, and the time that the "outing" occurs then affect their entrance and endurance in their ministerial occupation?

Each clergy member plays many roles that make up their overall identity. The ways that people navigate these roles affect their ability to enter and maintain occupations as professional clergy. "A role is distinct from cultural objects such as democracy and capitalism in that roles ultimately are used to construct the self" (Callero 1994). By this notation, a role is specifically used to define the self, and is defined as it is understood by the self. For example, "The role of golfer is experienced at the physical level of playing the game, at the level of interaction in discussions about the game, and in a more abstract cognitive representation of what it generally means to be a golfer. At this last level we can say that 'golfer' transcends any particular person or position" (Callero, 1994:232). This does not mean that cultural objects, by this definition, are entirely subjective or that they are trapped in the particular context of the person taking them on. Cultural objects, as defined by Callero, are intrinsically social, and require a shareable quality in order to be titled cultural object. It is important to understand the difference between roles and 
cultural objects because we might otherwise mistakenly conflate Christianity or Catholicism with roles as clergy. Christianity and Protestantism are cultural objects that exist for everyone to take part in, whereas the role of being a clergy person is something one has to obtain and self identify as. It is not available to merely state as a role or identity without effort.

Within the pragmatic framework of Callero's role theory, these cultural objects are used in ways that advantage the individual in a framework he has titled "role as resource". Essentially Callero proposes that individuals use roles to put themselves in preferable places in their lives, and that our economy of roles gives us advantages and disadvantages according to the way they are allotted prestige or stigma by others. These roles, as cultural objects, can also maintain and create social structures that may foster new sets of roles and positions. One example of a structural creation via roles would be when a group of clergy members gathered to create the Metropolitan Community Church so that all Christians, not just those heterosexually identified, could have a place to worship and gather around their common beliefs. Their prestigious role allowed clergy to make a space where people of less prestigious roles could create bonds and bolster their role as queer Christians, and any other minority status they may hold. This action also created a space for people who were formerly in the role of other in relation to the larger Protestant culture. The following findings section includes an in-depth description of the ways clergy have used their role as religious leaders as a resource for themselves and other minority Christians. I will now move to outing and coming out, as it relates to these roles becoming a resource. 
In similar research on coming out among teachers, Dr. Rasmusen (2004) assessed

the use of coming out discourse in classrooms, and how those discourses could affect student teacher interaction. As Rasmusen (2004) stated:

Coming out' is the process through which individuals come to terms with their lesbian or gay sexual orientations. Coming out includes both learning about oneself and sharing that knowledge with others. It also involves coping with societal responses and attitudes toward homosexuality. The coming out process is very personal. It happens in different ways and occurs at different ages for different people. Some people are aware of their sexual identity at an early age; others arrive at this awareness only after many years. Coming out is a continuing, sometimes lifelong, process (http://www.queertheory.com/politics/coming_out.htm).

An important piece addressed in this article is how each individual may have a different understanding of the ways people come out and what that means to the individual and their audience. All of the ministers mentioned in Hazel's research with queer clergy, as described earlier in this section, spoke of the timing and means of their personal outing as an integral component to their entering and maintaining their positions. This is in some ways an acknowledgment of a queer theoretical stance which privileges individual meanings and perspectives with regard to identity. To locate her particular research in this queer theoretical framework, Rasmusen then adds that "putting aside the issue of different people's motivations in deploying discourses of coming out and the closet, it is important to recognize that these discourses are absolutely fundamental to contemporary understandings of sexualities and schooling, and, therefore they warrant closer scrutiny" (Rasmusen 2004:145). The same case can be made for the identities of clergy members, who deal with the social responses and attitudes toward their sexuality. This raises the question of temporal order for clergy coming out: did they come out before or after 
ordination (or at any other crucial point) and how does that affect their endurance?

One school of thought regarding coming out would point out that being out to students creates a safe space where students can feel open about themselves and removes some of the hierarchical tendencies of instructor student relations (or clergy congregant relations). Another perspective of outing insists that the discourse surrounding coming out forces sexual and gendered minorities to come out, and does not allow for individual interpretation of how and why to do that. Rasmusen stresses the importance of looking at the power behind all of the discourse that make outing and coming out possible, or impossible, where those discourses originate and how they change. In their overt public position, clergy have great pressure to disclose who they are, and are seldom allowed to remain closeted should they wish to. This emphasis on outing in their occupation is similar to other helping occupations, wherein the person offering the council (in this case clergy) is expected to be forthright with their beliefs and philosophies in order to ensure a trusting relationship with those they serve (Alpert Et al. 2001).

A person's relationship to the closet and coming out is also greatly affected by factors/indicators such as race and age (Gross 1993). The "Closet" is argot used to note the state a person is in when they have not disclosed one or more identity or role they possess to others (most often referring to a gender or sexual identity that differs from the norm). People who are older or younger than the culturally consented age of sexual activity are not as prone to disclose their minority identity. Similarly, people of minority ethnicity and racial identities are often seen first by a perceived outward identity, and are less likely to be expected to disclose their sexual and gendered identities (Alpert, et al. 
2001). In a different way, this of course brings up the classic issue that heterosexually identified persons are almost never expected to explicitly proclaim their gender and sexual identities in the way that queer identified persons are (Gross 1993). In sum, persons of ethnic and racial minority identity often face less pressure to come out because they already belong to a subjugated social category that outsiders identify them with and understand them by. Heterosexually identified people do not have to come out in the same way as queer identified people because their majority identity status is assumed of everyone, and is the identity that many queer persons have to come out as "other than" or opposed to. An example of the importance of sexual identity for clergy can be found in the story of Reverend Gene Robinson, who was elected Bishop of the Episcopalian Diocese of New Hampshire. Robinson was forced to discuss his sexuality at length, whereas his heterosexual colleagues had to do nothing of the sort (http://www.nytimes.com/2010/03/18/us/18bishop.html?ref=v_gene_robinson). His sexual identity is one of the most widely known media stories of a queer clergy member to date. Aside from these individual level role related issues, queer ministers can also use their identity to be a part of the larger gay, lesbian, bi, trans (and many more categories and non-categories) movement for social justice (Alpert, et al 2001).

\section{Identity Theories}

Many queer ministers identify with the larger gay and lesbian civil rights fight that has been waged since the early 1960s (Hazel 2000). Their position as religious leaders gives them the power to influence, not only congregants, but the larger polities which govern their institutions. Many ministers feel that their position of power and 
governance in their institution is their part of the larger fight for equal rights and justice for queer people everywhere. This attachment to a justice movement is often acted out through ministers' support of legal issues (e.g. the gay marriage debate), and for some has been mentioned as a center of encouragement toward their initial entrance into ministry. In addition, ministers in previous research mentioned that their ongoing fight for civil rights and equality were a major source of encouragement toward maintaining their positions (Wilcox 2003).

Movements for social justice, like the one currently growing for gay rights, require strong levels of cohesion and identity salience in order to sustain membership (Edsall 2003). Members of movements often have other important social roles that conflict with their membership, and whether they choose to stay and for how long needs to be assessed in order to learn how individuals maintain membership and identity with these movements. This element related to how people endure their position in ministry and in any sort of movement, despite any biases or discrimination they may face, has primarily motivated my second research question. From the cultural perspective group identity is "the ready-made set of endowments and identification that every individual shares with others from the moment of birth by the chance of the family into which he is born at a given time in a given place" (Stryker 2000:22,23). This definition focuses on the ascribed statuses we are born with and have no effect on. These statuses may fit in some groups, but alone, do not explain the complexity of group identities and how they vary.

Stryker outlines Identity Theory and Self Categorization, and combines the two in order to discuss their synthesis: social identity theory. These theories bring in the 
conscious and subconscious decisions that are not necessarily attached to ascribed statuses, but that are selected/recognized as salient identities. He then describes the difference between role based identities and collective identities. Role based identities are situationally specific, meaning they do not shift or vary. For example, the role of clergy exists in an institutional structure, regardless of who occupies it. Collective identities are those that exist via a shared understanding that a group has consciously or subconsciously agreed upon. These two types of identity create separate results for the actors, and must be assessed separately. Queer clergy identify individually as religious leaders, but collectively as Christians, members of a congregation, and in some instances as participants in the GLBTQQI or gay rights movement. Levels of identity with movements may partially explain how clergy members manage to endure the heteromasculine nature of their occupations, while mitigating seemingly paradoxical identities (Stryker 2003).

Stryker then describes how Identity Theory grew out of the Symbolic Interactionist paradigm. "The theory's basic proposition becomes: commitment affects identity salience, affects role choice" (Stryker 2000:27). Here the author is making the connection that the level people choose to be integrated into a movement reflects an identity they have chosen, which is simply to be a member of that movement at a specific level of participation. The salience of that identity, or the member's amount of engagement in a role, affects the salience of their membership. Identity Salience, As Stryker defines it

"Represents one of the ways, and a theoretically most important way, that the identities making up the self can be organized. Identities, that is, are conceived as 
being organized into a salience hierarchy. This hierarchical organization of Identities is defined by the probabilities of each of the various identities within it being brought into play in a given situation. Alternatively, it is defined by the probabilities each of the identities have of being invoked across a variety of situations. The location of an identity in this hierarchy is, by definition, its salience" (Stryker \& Serpe, 1982: 206).

The level of salience (noted by other members, as well as the individual) will affect role choice within the movement or role.

Stryker's main goal in his group identity theories is to outline what is the best theory of identity to use in order to assess why people stay in movements and roles, despite different levels of commitment and exterior forces/identities. Stryker's answer to this question is: "Leaders remain as leaders when their social relations are circumscribed by the party-when their spouses are also party members involved in party activities; when their friends are drawn from party ranks; when, in short, they are isolated from relationships external from the party" (Stryker p.31). The social connections and outside identities (partner status, parent status, etc.) that a minister chooses to enter are paramount to their salience in the movement. This economy of identities is used as a way of looking for variation in movement identity, and assessing the probability a member will remain a member. Stryker's work on role salience and group cohesion helps to assess the ways clergy manage to endure their position in religious institutions, by providing a theoretical background as to how positions in institutions are maintained. I use the term movement here to refer to minister's involvement in the GLBTQI activist movement for civil rights, and the nexus of religious leaders' involvement in that and other movements for the betterment of all people through their ministries.

In sum, Stryker purports that there is no sure way to determine why members and 
leaders of movements stay or leave, but that social identity theory might bring us closest to this understanding. These theories of movement identity are relevant to my research for several reasons. First, there is an emphasis on conflicting identities within groups. Many of the clergy members that I interviewed expressed the sense that they are part of a "pride" movement for the rights of gender and sexual minorities. Understanding how they qualify their membership in that group, and what that means to them is crucial to understanding their experience in the group. Whether they choose to remain in their leadership role, in the face of opposition from more traditional religious polities, and if they are working with or against those other organizations is also an important element of this story (Wilcox 2003).

Next, Stryker's theories focus on the conflict between identities, group identity cohesion, and group leadership endurance. His work on how and why people in positions of power in social movements manage and maintain their positions of power is particularly pertinent here. Do clergy have different understandings regarding their place and definition of their individual and group identities, and how does this relate to their ability to endure in those positions? Is there a conflict due to the paradox that may exist between identities, and if so how is this affected by different levels of salience? Will this be different for folks who work in faith traditions that were open and affirming of sexual minorities from their inception when compared to those that became open and affirming as part of their evolution (Wilcox 2003)? The level of commitment and outside support for each clergy member is highly important for their position in the culture. Stryker is focusing on a more integral group dynamic, and movements that are unified in different 
ways, but conceptually we are looking at similar phenomena.

When queer clergy take on their traditionally heteromasculine role within a denomination there are many possibilities for barriers to their access to those positions, and their likelihood to maintain those positions are affected. The ministers I worked with were all out to their faith communities, but when they came out and how coming out related to the timing of their seminary and ordination was a key factor in how they were able to enter their occupation. The barriers clergy members have dealt with throughout their professional religious lives manifest from stigmas attached to their identity and role, and ministers are faced with the task of navigating their identity and their occupation in ways that others might not experience. To what degree is a minister's identity and self categorization affected by stigma and tokenization of their role, and what effect does that have on their entering and maintaining their position? What are some of the factors that help them enter and maintain those positions, despite any obstacles that might hinder those choices? 


\section{CHAPTER 3: Methods}

The following section outlines the methods used to locate interviewees, collect data, and analyze transcriptions of those interviews. First I will describe the process of obtaining contacts and setting up interviews. In the twelve in-depth interviews I conducted with queer clergy members (one transgendered person, four women, and 7 men) everyone was out, and actively working as ministers in various faith traditions. All participants are white, and in an age range from their early forties to their late sixties. All of the women self identified as lesbians, the one transgendered person I worked with self identified as transgendered, and all of the men self identified as gay (All of these characteristics are included in Appendix A). Each individual was eager to work with me on this project, and I had no trouble persuading folks to discuss their experience. As an example of this, every clergy member asked me to use their real names in my write up of their story (which I had to decline per our prior anonymity agreement).

Next I will discuss how the interview process was conducted, and how the interview guide was created from pilot interviews and research instruments. This section also contains a detailed description of grounded theory data coding and analysis, which I employed to search for patterns and make sense of the transcribed interviews. The coding and analysis began by simply reading the transcripts several times on a word-by-word basis to locate and establish themes, followed by memos written concerning the specifics and aberrations within those codes. Finally, codes and themes were connected and compared to previous research and theoretical literature.

Later in this section I will be telling the story of how this research project came 
about, what transpired during the interview process, and what themes emerged from the transcriptions. Themes will not be written in order of importance, rather in the order they were addressed in the interviews, as there is no coherently objective manner of qualifying each subject. The order of themes is purely organizational, and the level of relevance for each theme (measured according to the participants' responses) will be outlined in the following discussion section.

\section{Participant Recruitment}

My initial contacts to begin this snowball sample were three ministers who I located simply by asking everyone I knew if they knew any women clergy in or around Portland, Oregon. As I stated previously, once I conducted pilot interviews, intending simply to use those discussions to inform my question guide, I recognized that all of the people I had been talking with identified as lesbians. After an extensive inquiry into the level that queer identified clergy had been researched I discussed my current research topic with one of these ministers, and she promptly turned me toward a local Portland organization called Community of Welcoming Congregations. The Community of Welcoming Congregations (CWC)

is dedicated to the full inclusion and equality of transgender, lesbian, bisexual, gay and questioning persons. CWC works to: provide public voice for 'TLBGQ and Allied People of Faith', engage religious/spiritual people to work on public policy honoring TLGBQ persons, network with regional denominational groups: Lutherans Concerned, More Light Presbyterians, Reconciling Ministries Network, UCC LGBT Concerns and the Church, and Integrity" (http://www.welcomingcongregations.org/?page_id=19 ).

Working with the executive director of CWC, I was able to locate approximately 
fifteen additional clergy members, from various faiths to interview for my project.

Following multiple telephone and email exchanges, twelve of the fifteen clergy members agreed to interview with me. The remaining three were either unavailable, or from faith traditions that would not be comparable to the rest of the population. One of the twelve clergy I did interview is a Gnostic minister, and the religious context of his experience was disparate enough that I will not be able to use that interview to look for patterns and differences in clergy experience. I hope to add other faiths to this study in future research, and I will discuss that in later sections.

This population of out, queer identified ministers, was selected as part of an emergent process that began with a desire to study women of clergy. I chose this population based on a conceptual fascination with people who chose to enter contested spaces or occupations, coupled with a deep interest in the sociology of sexualities, religion and gender. As stated previously, some inside informants I conducted pilot interviews with brought it to my attention that they all self-identified as lesbians. I examined the literature review I had amassed, and realized that I did not have any information on queer clergy. Upon further library investigation, accompanied by frequent discussions with the few authors of theology and social science in the field, I noticed that there was little to no research regarding the experience of queer identified clergy, which prompted me to refocus my inquiry to include any and all sexual and gender minority ministers.

The clergy members I interviewed were all parish ministers, meaning they serve at an established church that congregants attend. "The parish is the context in which 
clergy most frequently relate to laity and the public at large and are thereby the most visible" (Carroll et al. 1983: 3). In this way parish ministers are likely to have the best understanding of barriers faced by queer clergy, because they interact with more people than ordained clergy in other positions. All but two of the clergy persons I interviewed work for a Protestant denomination. I chose to limit my study to protestant ministers for several reasons including: there are not enough out queer religious leaders of other faiths in the area to create a comparative analysis and test the reliability of my interview instrument, it may be problematic to compare the differences of persons' experiences who come from disparate faith cultures, and finally, I was raised in a protestant faith tradition and have a good grasp of the beliefs and practices of many protestant denominations. One of the non-Protestant clergy was a Unitarian Universalist minister, who felt that his experience was similar enough to that of many Protestant clergy that his story could be compared with those of Protestant ministers. The second non-Protestant minister was a Gnostic priest, whose religious culture is disparate enough that I was not able to use much of his interview for comparison or to add to this narrative.

I should state here that I am not a member of clergy, have no intention of becoming ordained, and all limitations related to my outsider status as researcher will be discussed with participants to demonstrate a high level or transparency on my part. I also do not currently identify or affiliate myself with any organized religion or faith tradition. I stated my identity to participants, when asked, regarding my lay position with relation to clergy as well as my spiritual, sexual, and gender identity. Throughout the interview process I made a point to explain my religious/spiritual position as one that enables me to 
maintain a minimal level of bias toward different traditions my interviewees identify with. Several clergy members agreed that my agnostic laity position was advantageous in assessing their stories of ministry call. If I had come into this research from a specific denominational affiliation I might be inclined to view others' experiences through the lens of what I consider my spiritual reality. In this way, my religious identity as an agnostic is a strength to my research approach.

I met with the three clergy members who had helped redirect my inquiry and compiled a list of all the queer persons who are "out" clergy members in and around the city. The director of the Community of Welcoming Congregations was one of my informants, and provided a wealth of resources for the interview process. Community of Welcoming Congregations is a national non- profit institution that works to aid churches in becoming more open and affirming to minorities (particularly queer identified minorities) in their community. I then emailed each potential interviewee, and included a copy of the letter of consent for their thorough review. Potential interviewees were quick to respond and schedule meeting times with me. I also received phone calls from people I had not contacted who had been emailed by my intended participants. All meetings were conducted at one of three locations: my office in the sociology department at Portland State University, the offices of clergy within their parishes, or in the privacy of their homes. Each of these locations was selected according to its convenience for the interviewee, as well as the high level of confidentiality afforded by private space. The folks I worked with could not have been more helpful, and were eager to share their stories with someone who wished to document their experience. In many ways, the 
snowball sample for this project created its self.

Interview Process

At each interview I began by asking participants to read the letter of consent, and giving them time to ask any necessary questions about my research as well as anything they wanted to know about me personally. If the interviewee was interested, I would make sure to spend some time getting to know them, and attempting to create as comfortable an environment as possible for the interview to take place. Each interview was scheduled for an hour, but if the participant wanted to continue I was willing to listen and discuss any topic they wanted to add to their piece of the research for as long as they wished. "If researchers do not establish rapport, they risk losing access to conduct subsequent interviews or observations" (Charmaz 2006:19). Rapport is pertinent to my research, as I do plan on expanding it into a larger study for future research.

Next I explained how the interview process would generally be conducted, starting with an approved list of questions formed by my literature review and preliminary interviews with insiders. I then explained that the questions would be followed by an open ended dialogue where the interviewee was welcomed to add anything they felt was essential to their entrance into the culture, followed by a time when they could address any current events that are affecting entrance in their specific church or denomination for clergy. As a closing note, I asked each clergy member to share questions they felt I should add to the list, to be asked of all clergy. In this way, the interviewees created a vital piece of the research, adding to the overall validity of this research process. As the only persons to truly understand their experience, clergy 
members are clearly the authority on what should be asked of their culture. "With grounded theory methods, you shape and reshape your data collection, and therefore, refine your collected data" (Charmaz p.15). This process continually boosts the validity of the research, by ensuring that the main focus remained where members felt it would be best suited. These refinements were sent to the Human Subjects Review Board (HSRB) for approval, and then added to the interview guide. The results of these different stages of interviews will be detailed at length in the discussion section of this document. All of the initial questions were consistent throughout each interview, and the nuanced pieces were added at the end of the session. I wrote detailed notes on the new questions, and will discuss these changes throughout the following chapters.

\section{Interview Guide}

Prior to the addition of questions and concepts from each clergy member I obtained questions from a survey titled, "Women of the Cloth" (WOC) which was primarily conducted through telephone conversations and mail surveys with over 600 women of clergy in the United States (Caroll et al. 1983). This study, conducted after some Protestant denominations began ordaining women in the early 1970's, used a list of nearly two hundred questions to assess the experience of women of clergy in their occupational lives. I sorted these questions and found several that directly related to my research. In addition, I included questions concerning demographic information for each clergy member and added this data to the transcriptions to be analyzed. The list of questions used for my research is located in Appendix B, and all demographic 
information in Appendix A. Some participants declined the demographic portion of the interview for various reasons, and a descriptive analysis of this information was not possible.

During each interview I recorded both my voice and that of the interviewee I was working with. In addition, I wrote notes on the key points of the interview, paying careful attention to any topics that arose which had not previously been addressed in my interview guide. Following each interview I went home and wrote memos about my interaction with the interviewee, the interview setting, and all of the new and intriguing information the participant had shared about their individual experience. I also wrote notes and memos about any obvious pauses in conversation, or clear points of intrigue or distaste related to the interview (for myself or the participant). All of this information was compiled along with the transcriptions for my overall data analysis.

\section{Analysis and Coding}

The book, Constructing Grounded Theory: A Practical Guide Through Qualitative Analysis by Kathy Charmaz was my primary guide for analysis, coding and writing up the findings from my transcripts. This process began with searching for themes and patterns on a word for word basis throughout the transcripts. Next I analyzed the transcriptions on a line by line scale, again searching for patterns and themes. Extensive notes (or memos) were written that outlined the reasons a quote was coded one way or another, what the outliers in a group of codes might suggest, how the code relates to previous research and literature and how one code relates to another. Memos not only 
captured thoughts for later consideration, but also helped crystalize questions and directions and capture connections and comparisons. "Memos give you a space and place for comparison between data and data, data and codes, codes of data and other codes, codes and category, category and concept, and for articulating conjectures about these comparisons" (Charmaz 2006:72). Memo writing is an essential element in Grounded Theory research writing, as it allows the emergent elements of the analysis to congeal and be assessed.

The themes recognized in both analysis strategies were then separated into categories based on conceptual similarities, and used to create codes by which all of the transcripts could be analyzed once more. I went back over the transcripts numerous times following the word-by-word and line-by-line coding and, re-analyzed the entire set of transcripts. The most intriguing element of grounded theory, as Charmaz describes it, is that the researcher is "constructing analytical codes and categories from data, not from preconceived logically deduced hypothesis" (Charmaz 2006:5). This enabled me to create analysis categories after reading the data I had collected, and then determine what it all meant based solely on the themes of the data. For such an exploratory project as this one, grounded theory is the best form of analysis to pinpoint what should be included in the following report.

From the analysis and coding six major themes emerged, for which I wrote memos and used to organize the related findings sections. Each theme is connected to the concepts of entrance and endurance and include anything that ministers stated as pertinent to those two main concepts. These themes were based on patterns that emerged 
from my initial line by line transcript analysis, as well as phenomena that clergy members had specifically noted as pertinent to the entrance and endurance of their occupation. These themes included: God's call, seminary encouragement/discouragement, childhood and young-adult influences, homophobia (internal and external), political activism, and anything relating to a clergy member's denominational policies.

Under the code titled "God's calling" I compiled any and all mention of a spiritual calling to ministry, and then separated these quotes and phrases into smaller categories that could more easily be written on. Similarly, for the code titled "seminary encouragement/discouragement" I amassed all statements regarding seminary experience, later categorizing them according to who they were related to (colleagues, parents or peers). Childhood and young-adult influences were slightly more conceptually separated into stories of childhood religious experiences that were related to parents, churches, denominations, spiritual experiences, and other less common indicators that will be discussed in the findings chapter. Homophobia was coded based on any mention of or allusion to prejudice, discrimination, or other bias against someone based on their minority gender or sexual identity (this included both internal and external). The code titled "political activism" was also determined based on a very conceptual definition of activism. Nearly any declaration of a desire to help the larger community, even those specific to the denomination a clergy member works at, was coded under this theme. Some of the sub themes within "political activism" included: a desire to change or affect church polity, the gay marriage debate, desire to be a role model for other queer Christians, a desire to change the homophobic tendencies in society, and others that are 
included in the findings chapter. Lastly, the code for denominational polity emerged from participant's frequent mention of the way their church's rules and laws worked, and how those things affect them. Statements related to denomination policies were collected and organized according to how positive or negative they were intended to be, as well as their origin, which included their relation to the church politics, the congregation, the level of authority each participant felt they hold, along with several other themes. Overall this analysis process was extremely educational, and made me truly appreciate qualitative inquiry to an even higher level than I already had. 


\section{CHAPTER 4: FINDINGS}

In this chapter I will discuss how the eleven ministers I interviewed feel about entering and maintaining their occupation. This section is specifically a space for the voices of clergy members to ring loud and clear with the narratives of their entrance and endurance as professional religious leaders. These findings will be partitioned by themes which emerged from the iterative process of transcript analysis, followed by a discussion section where I will summate the ways these findings connect to my two driving research questions, my literature review, and my theoretical framework.

\section{God's Calling}

I originally began interviews by asking what influenced each clergy member's decision to be ordained and become professional religious leaders. The first person I talked with was quick to correct my choice of wording regarding her position. "It's not a choice; it's my calling from God. It's what God wants me to do with my life. It's definitely not just a choice. I would reword that first question and ask people about their call story. Everyone will be more comfortable with that," Ezra aptly pointed out. Ezra is currently working toward the position of acting minister in the United Church of Christ. From here I proceeded to give her time after each question to help me fine tune my interview guide into a more sensitive tool that would bare as little effect on a participant's response as possible. I continued to leave time, as noted in the previous methods section, for each clergy member to discuss any issues or suggestions they might have for the research its self. This process allowed me to direct my research toward the current 
interests clergy were concerned with, while simultaneously better answering my own research questions.

Several clergy mentioned a need for some direction and motivation from colleagues and peers in order to recognize their call at the outset. Mary is a 55 year old, lesbian identified, MCC minister and Wiccan Priestess. Raised Methodist and Catholic, Mary regards herself as spiritually multilingual. She took years to find her place in ministry, and was finally convinced by a colleague during a conversation over coffee. Mary's call seemed crystal clear to her friend, who asked her,

When are you going to realize your call to start groups in cities that may already have MCC's, but they're not reaching women because they're too patriarchal?" Mary then put these words of encouragement alongside her lifelong contemplation of religious leadership." She pulled it right out of me, and I thought, time to open my mouth and step up. So then I began the clergy process at MCC and was licensed in 1985.

Rebecca, a 58 year old United Church of Christ lesbian identified minister, was lead to an understanding of her call to ministry by a fellow Christian while attending a war protest in South America. As she stood atop a large ceramic planter, watching the demonstration take shape her friend asked her what she later realized was one of the most important and influential questions that had been posed to her at that point in her life.

Fabiola turned to me and asked, in Spanish,"Are you a Christian"? And it was, just like in the movies. When the sound gets turned down, and the movement stops. And through my head went pictures of anyone who had ever meant anything to me. My mentors, my heroes. People like MLK, and the Barnston Brothers, and Lou Anne Coughlin, and my mom. My uncle John. Sister Corita. All these people, and it was like, wow they are all Christian. And the next thing that happened, I am not kidding, I saw these giant flip cards containing all the words I had always lived my life by. Things like; love one another, be kind to one another, do unto others as you would have done unto you. Walk the extra mile. Turn the other cheek. And I'm thinking wholly crap, this is all Christian. And I turned to her and said, Si, soy una Christiana. But the sun came back up, and I'm 
standing there on that planter thinking, wholly shit! What do I do now?

Rebecca did not immediately see this as her call, rather it was the inquiry that started her thinking critically about what she had done in her life thus far, and what she felt compelled to do with the rest of that life. Soon after the events in South America Rebecca decided to apply to seminary school, with the notion that she needed to begin moving her life in a direction that would at the very least allow her the option to join the clergy.

Rebecca had been an activist her entire adolescent and adult life, and was quite accustom to standing up in the face of opposition and telling the world what she felt was right and just for everyone. This made ministry seem like a "no brainer", as she so eloquently put it, and she has now been ordained for 11 years.

Other clergy mentioned that their call was less aided by friendly encouragement, and rather was a lengthy process of introspection and self reflection. This understanding of their call had not been clear to them their entire lives, rather it came to them later in life as they began to revisit their spiritual understandings of the world. These ministers looked back to their life histories in search of better understanding of what they wished their future to hold. Ezra, in particular, told a story of her call to ministry that came at the same time she began to identify as a lesbian.

So for me personally, I had a sense that I had a call, and that I was a lesbian in the same year. I'm not sure in the beginning that I felt called to do specific LGBT ministry. Either for me or this more out of my place of faith that I felt really called to be in leadership in the church. At that time I was Presbyterian and we had to work hard for the educational requirements for that. So it came out of that deep prayer life where I felt that this is what I was called to do.

Ezra was working through more than her call to ministry at the time she began to explore ordination as a possibility for her career path, and this dual nuance in her life caused her 
to take some time becoming comfortable with either role and identity. She also spoke of a lifelong understanding of her faith that made her path to ordination a sensible one, once she realized it was what she wanted.

Reverend Gabriel, a 47 year old, gay identified, minister of the Metropolitan Community Church (MCC) also sees his call as a process that he came to through many conversations and deep reflections of the events in his life.

It was about a year, or a year and a half before I attended an MCC in 1983. Shortly before that, in the early 80 's, in my coming out process, I would say I had my first conscious sense of being called to ministry. I had always taken the life of the church seriously. I had always been involved in the life of the church. This notion that I might actually be called to ministry was not something I had been aware of. In 1981, I was driving down a highway, just randomly thinking about things, and for the first time in my life, heard a voice that was not my own inner voice, saying I want you to be a minister. I immediately thought, yeah, I'm gay, so that's not going to happen. That was the first conscious clear sense of being called to ordination. I immediately dismissed it, because I did not see, at that time in the early 80 's, and denomination where I would be able to do that as a gay man. About a year later was the first time I attended MCC. I became very involved as an active lay person.

Gabriel has now been a minister for roughly 5 years, and feels his experience in an open and affirming congregation has changed his life entirely. Gabriel was one of the three ministers I met with initially, in an effort to add to and clarify my interview guide, and in all interactions with him he indicated the importance of his call being a slow and educational process.

Still, some ordained queer clergy knew from their earliest recollection that a life of ministry was where they belonged. Many of these folks had been an integral part of their church's culture, meaning thy had been heavily involved in their church and sensed a strong connection to their faith from a very young age. Ruth, for example, asserted that, 
It was a calling. I had been in the same denomination all my life. I was active. My activity all along I would label as ministry. Which dates back to about 1975 or '76. And my teaching history I view as a call. Then in 2001 I experienced the very clear call to ordained ministry. That was a very sacramental ministry. And that, if it hadn't had the sacramental element, I think I would not have been ordained, because I could do most anything I wanted to within the Episcopal church as a lay person. So it was a call.

Ruth then continued to describe other elements of her life that she identifies as a call, and how these things were part of a natural procession to her being ordained. Ruth is a 67 year old Episcopalian minister, and a history professor on week days. For many clergy, like Ruth, there was very little mention of barriers or discrimination in their process of ordination, and many of them only mentioned positive experiences in their path to ordination.

\section{Childhood \& Young Adult Influences}

The majority of clergy I spoke with mentioned a clear call to ministry that began and persisted throughout their childhood and early adult stages of lives. That is not to say that this call was as clear during adolescents as it is today, rather that it changed and shifted in importance and intensity throughout their growth process. All of the ministers I spoke with indicated gaining their sense or socialization of the religion they identify with at a young age. It is less common for folks to come into religious belief systems as adults, therefore it makes sense that many of the participants I spoke with mentioned their call coming at a very young age.

Episcopalian Reverend, Titus, was intrigued by the clergy he met as a child, and knew from his first encounter that he wanted to join their ranks. He, like several other 
participants, noticed a special quality in themselves that they felt aligned with their church's ideals or inner workings.

I think I've been called to sacramental ministry, so priesthood, since I was a child. I was raise in a large Irish Catholic household. The church was a very large part of my identity growing up. My mother was very involved in the preparation of the space for liturgy. And so I would go with her, when she was setting up. The whole idea of being part of that inner sanctum, sort of holly of hollies was fascinating to me. And so, if there was a defining event, I guess it would have to be participation in the liturgy. Being an alter-boy, and always knowing that I wanted to do what the priest was doing.

Titus transitioned from Catholicism to the Episcopalian church in his adult life, finding the Episcopalian faith very accepting and welcoming to his other identities. The Catholic Church is not ordaining women or queer identified persons yet (and possibly never will), and the Episcopalian church with its similar "high church" culture is a comfortable fit for many ex-Catholics like Titus. Reverend Jude spoke similarly of his attraction to what he saw in the Catholic Church as a child. "Well. I think I've always been attracted to the high church ritual, since I was a little kid. Anything that seemed to be a contact with other worldly dimension of the universe sort of attracted me." Other ministers described a path to clergy that came from a love of god that was not necessarily tied to a specific church or faith tradition. Reverend Joel was one minister who did not speak of his path to faith in terms of past religious institutions.

As a child I always did feel a spiritual connection. And that connection and my conversations with god...that time and my first conversations with god, the earliest memory was about three. And that's really been a source of strength in my life. It helped me get through a lot of difficult years.

Joel went on to describe some of the hurdles he had overcome throughout his life, and how 
This understanding of a religious calling to ministry during childhood was not as smooth a path for some ministers. Several participants mentioned struggling with internal homophobia, via what they had been taught about being gay through their earliest church experiences. This will also be further addressed in a following section where I delve deeper into homophobic understandings clergy expressed. Gabriel, for example, tells of mentioning a conflict between his Christian identity and his gay identity at a young age.

I was raised in a religious family. My Presbyterian background, we were involved in church background all of my growing up years. The life of the church was always central to my own growing up. I had, in some ways I would call it the "classic struggle" of being gay and also being a committed Christian.

Joshua, a 47 year old United Church of Christ (UCC) minister, experienced a strong influence from his parents toward a life of religious devotion. As did several participants, Joshua expressed an early concern over his parents seemingly arbitrary method for choosing a denomination.

I was born in Miami, Florida. My father's family was from America's Georgia, so very southern Baptist. My mother's family was Disciples of Christ. My parents, when they met, didn't like each others' churches, so they drove around Miami and found a pretty church. That's the story of our family. So...the Presbyterians have the prettiest churches because they have the most money. Then my parents were asked to go out and be the voluntary directors at a little mission youth church. I went to Stetson University, a little Baptist school.

His parent's willingness to change denominations may have made it easier for Joshua to simply select a denomination that would accept him in his adult life, rather than trying to maintain a relationship with the denominations that he had grown up in. Joshua also mentioned that he enjoyed the bottom up polity of the UCC, and he had not been encouraged by the heavy bureaucracies of his parent's traditions. Several ministers mentioned the importance of non-hierarchical congregational polity styles in their 
traditions, and I will outline these in the following discussion section.

Reverend Ezra Described a barrier she felt was critical to queer clergy as they search for their place in religious culture, and deal with identity competition as a result of social stigmas.

Lots of us, GLBT clergy have similar paths because the traditions that we're born into, or that we grow up in as adults won't ordain us. When they came out - when I came out, my family was great. It actually wasn't even a surprise. They struggled more with my going to seminary than coming out. By I think for some people who come from families that are not as accepting, that come from faith traditions that are not welcoming, it would be good to ask folks how they reconcile, or how they dealt with those attitudes themselves...did they ever question whether they were okay with god? That's kind of a good question to ask.

In the second part of this statement Ezra is making a suggestion that I look into issues of internalized homophobia that queer clergy may have experienced as a result of their more conservative and homophobic you church experience. Many of the clergy members I worked with did express a sense of self hate or internalized homophobia that I will discuss further in this section as well as in the discussion section of this document. Still other ministers spoke of never having plans to enter the ministry until their adult years, and this was often promoted through friends, religious colleagues and other peers. The following is an example of such a case, as experienced by Luke, a 47 year old Unitarian Universalist (UU) minister who has been an ordained minister for more than 15 years. Regarding encouragement toward his ordination, Luke said,

Well, um, in my family there is a tradition of clergy, so part of it was expectations growing up. I think that as an adult I um, my first career was as a newspaper journalist. That was lacking a spiritual or relational dimension. And I was raised a Lutheran, and fell away from that tradition as a teenager, and uh, I was wanting something with a spiritual dimension. When I went to seminary I thought I would likely be a counselor, and I found that Parish was a good fit for me, so I ended up going into the parish and I've been here since. 
Luke's experience is a preview of the stories that are shared in the following two sections, in which clergy were encouraged and discouraged to become ordained through many different facets of their lives.

\section{Seminary Promotion}

I have, thus far, outlined clergy's entrance experiences relating to what they discern as a calling from God, as well as influences from their youth. The primary focus for this section will be on the ways seminary experiences encouraged or discouraged clergy to maintain their path toward ordination. Seminary is a necessary educational process for ordained clergy in most Protestant faiths, and was noted as a seminal factor in the process of ordination. Students work with academic scholars and past denomination polity members who have a great affect on the way they will understand their denomination, and their place within it.

Amos, a minister at the Church of the Brethren, came to his seminary schooling after several other academic endeavors he did not feel were particularly the right path for his life. In addition, he selected his seminary based on a separate political activist identity that he states here.

I got out of 6 month of active duty, back in Salt Lake where my wife had been while I was in the army, and pretty quickly decided that I wouldn't pursue that $\mathrm{PhD}$ program, but would try to study religion and philosophy some place. Within 
a few months I had applied to Pacific School of religion in Berkeley and to the church of the Brethren school in Chicago. There were several incidents helped me decide on choosing Bethany in Chicago. Mostly because of their peace witness, this was the rise of the Vietnam war in the mid 60's. In the fall of 65 we moved to Chicago and I started seminary.

Notice that along with his interest in peace activism and seminary schooling, Amos mentioned being married when he attended seminary. Amos was out to his wife from the beginning of their relationship, and maintains a healthy relationship with her today. They made the decision separate once their kids were out of the house, and move into intimate relationships that satisfied them both more fully. They currently work at the same church, and are a strong source of encouragement for one another throughout many facets of their lives. Three different ministers mentioned being married in heterosexual relationships prior to coming out publically and either changing the dynamics of their relationships, or abandoned those relationships entirely in search of connections that better aligned with their sexual identities.

Ruth experienced what was likely the smoothest transition into seminary. Of all the folks I worked with. She had already been working in her church for many years, and was attending the same church she had grown up in. The denominational leadership essentially required that she go to seminary for a few courses so she could share the experience with others.

I chose the school because it was relatively close. I went to Church Divinity School of the Pacific in Berkeley. And my bishop here was willing to be incredibly flexible, because, I do not have an M. Div. I went to seminary for one semester, and then took three correspondence courses. I chose it mostly because it was close. I also knew it was a gay friendly school. So, I figured that my sexuality would not be a huge issue, but also not be a barrier at all. I had at that point, 30 years of experience studying and developing liturgies. Which is a huge part of the Episcopalian church. It wasn't that I didn't have things to learn. When he told me 
the requirements he had, it was that I spend one semester in seminary, and he did not care what I took. I just needed to have the experience of living in a seminary community. His other requirements for me were that I complete the general ordination exams. Of course. All the various groups that got to discern whether my call was real, whether it continued to be real and legit, and that all of those groups would continue to say yes. And they did rather quickly.

When I asked Ruth if she was promoted by her peers to go into seminary and pursue ordination she replied with the following.

That's a given. You have to be promoted in order to be ordained. During the second semester I was teaching full time here and doing online course. I had a conversations with various people. Most notably the person at the diocese that regulated employment. And identified a congregation to become a part of, to work in. That's how that process works in the Episcopalian Church. Normally when you do an M. Div, your third year you gather materials that will then be sent into the national database. It turned out I didn't need it, but it would be helpful in terms of looking for other positions now.

For these unfettering seminary experiences Ruth was able to focus other aspects of her experience with identity and her clergy position throughout our interview. She was one of the other clergy who were previously married, and have children with their former partner. Her son came out approximately two weeks prior to her disclosing her sexual identity, and they have since bonded over their mutual comforts and discomforts with these identities. This is a very specific (and micro level) example of the ways people bond over minority status, as noted in my theory section regarding group and movement identity. Ruth is one of two ministers who had children come out around the same time they did, and this seemed to help everyone involved through that arduous process.

The clergy who began their path with some reservations about becoming ministers, as mentioned in a previous paragraph, all felt that their entering seminary was not necessarily a guarantee that they would pursue ordination. For Gabriel in particular it 
was more of the creation of another path his life could take, than a necessary step toward

ordination.

My decision to go to seminary was that, if I decide to become a pastor, I will want to have gone to seminary. I was still doing this dance of avoidance. Of saying yes to becoming clergy. Seminary was the accepted standard at the time. A Master's of Divinity or cultural equivalent. So, entertaining this notion that I may become a church pastor, which I was avoiding, I said yes to going to seminary. I will say, within the first month I chose to enter the M Div program, because It was longest. I s till was not convinced that I was going to do it. But within a few weeks there were just so many things that happened that convinced me that was what I had to do. I was sitting in seminary class. Hearing information about the Bible, about Christian history. I found myself saying, that is so exciting to me. I found myself saying, how do you take that to a church and make it come alive? How does that preach. I found myself wondering how that would apply to a real life application. It occurred to me that I was taking the steps of fulfilling the call to pastoral ministry. The short of it is, I have never been happier in my life as I have been as a pastor. It feels that all of the gifts that I have are called into play in one way or another. I initially studied as a professional musician a number of years ago. Part of that was, again, it was a good thing. I got moments of awareness. Some moments of crystal clear call. But, that's really the longer short answer.

Gabriel has now been in his pastoral position for about 5 years, and feels supported by his community and culture at MCC. He attributes a portion of his positive experience to his ability to be out and open throughout his seminary experience. He summed the general consensus of his seminary school's attitude with the following.

You know, we don't think people should do this, but we don't talk about that here. So it was a liberal seminary. Generally. Even though some of the folks were more conservative. I had no qualms about being openly gay in seminary. Speaking about that in my classes, and making an example of that when necessary.

Gabriel's current position at MCC is very similar regarding his ability to be open and, as stated in this eloquent quote.

They welcomed newcomers, and everyone turned and looked at me. By the end of that day it felt like I had gone to church for the first time. It was the first time that all of me went to church. I'm not an impulsive person, but I was focused. This is for me. I never really looked back. The next membership class I attended, I jumped in whole heartedly. It was in some ways a non-decision. It was not a 
cognitive or rational decision. It was this is where I'm supposed to be. There are moments where I don't love MCC. But the decision to join MCC was simply made. It was very clear to me. This was my journey. This was where I could be where I was called to be.

This piece from Gabriel points to a realization that occurred at different points in each clergy member's life, but for Gabriel it took the support and encouragement of all persons involved to help him recognize his call. Gabriel's feelings concerning his current position are an illustration of the importance of group cohesion and collective support systems for people in sexual minority categories.

Reverend Joshua likely had the most eventful and tumultuous seminary experience of all the ministers I worked with. He went from enduring the possibility of being kicked out of school for his sexual identity, to starting the first gay alliance on the campus. His experience speaks volumes of what one person can tolerate when faced with conflicts between two of their most important identities. Some of the negative elements of that experience will be told in detail in the following paragraphs titled homophobia, and herein are the primarily positive (coupled with a few less positive) aspects and leadership opportunities he encountered throughout that experience. I will begin with a statement he made about his parent's reaction to his desire to attend seminary school.

I called my parents in my junior year of college and said that I would really like to continue wither religious studies. I am really interested in this stuff. Well, my parents heard that and said, oh my god, out son wants to become a minister, which is the best. It's better than a doctor. You're saving souls. So now, there is this new level of expectation. So, going to Princeton University and studying.

With this positive blessing from his family back home, Joshua went into his time at Princeton with all the encouragement he could want. He also had the knowledge that he had been admitted to a very prestigious program, and would be highly employable upon 
his completion.

So, I go to work with the gay alliance, and I got to preach. So, the next year Princeton University hired me and I got to work with the Gay Alliance at Princeton University. We set up the first Gay Awareness week at Princeton. So, when they trace the gay alliance back now, it goes all the way back to that seminarian, and that's me. We started "gay jeans day", which is kind of a standard now. So, in college nobody had anything but jeans. If you support gay rights, wear jeans on this day. So, obviously they were outed. We had this one guy in the gay alliance, and he's a famous writer in New York today. But he was sort of our spokesperson. And he writes back, "yes, every day gay and lesbian people stand at the mirror and wonder, what am I going to put on today?

Several interesting concepts are drawn out in this quote from Joshua. First is that he started the first queer group at Princeton University. Joshua pointed out that, although Princeton is in a liberal area of the United States of America, it was a very conservative school when he attended. He considered quitting several times due to the homophobic nature of his interactions with colleagues and peers, but he was to able to endure their discrimination and finally graduate. During the process of dealing with the biases of his colleagues, Joshua took a year off from seminary and worked a church in New York as he was getting acquainted with his current partner of more than 20 years. When he returned he was in dire need of employment, so he phoned the university and asked if he could make a job for himself.

So, I called up, and I was very direct. I said, you had this guy 20 years before me, and you have this Campus Pastor for Gay and Lesbian Concerns. I'm the guy, you should hire me. And the woman, bless her heart, said sure why not. We'll give it a try. So, we set up a gay and lesbian crisis line, and I sort of ran that. Let me think of what else we had. Anyway, we had a bunch of gay and lesbian activities. A gay dance. And it was wonderful, accept it only paid me 600 dollars a month. Which is very difficult, because I was not in the dorm.

Joshua found a church to work in once he finished seminary that would become his open and accepting home. He realized that he had to leave the Presbyterian faith, as the polity 
was not budging in their stance on ordaining queer clergy. Almost half of the clergy I

interviewed mentioned having to switch denominations once they decided to seek

ordination, as the churches they had grown up in were not accepting or welcoming to

them in those positions. Three of those who switched faith traditions were formerly

Presbyterian, and of those three two went to the UCC, and one switched to MCC. Of the

UCC church he found after his ordination, Joshua had endless positive things to say.

Every congregation makes up its own stuff. So, I come back from Baltimore, where the National is handed down, once again. You know, you're not welcome. And, Charlie comes in to the office, and I'll never forget this. This is the biblical story where, Jesus is at the River Jordan, and he's getting Baptized, and the skies open up. So, Anyhow Charlie is coming by and he says, that the table is already set for you, so you cannot say that you are not welcome, because you are at a UCC church. This church wants to ordain you. So, maybe your calling is to be an activist at the Presbyterian Church and to bang on the gates. But you can't say that you're not welcome, because the table is set for you. You don't even have to leave your church. Most people have to leave and find another one. But here they are the same. So, I go back to seminary and pick up all the necessary courses on UCC polity. Which is a joke, because the national church wants all churches to be open and affirming. Every single congregation has to decide for themselves. This church down the street decided in a very direct way to be open and affirming. So, that's how they hired me. But, that's how I got where I am. SO, I'm in a great place, I love the people, and I love where I am.

The seminarian road to ordination also held some positive surprises for Joshua. Some of his professors reacted very well to his identity, and were supportive of his drive to become clergy. They were there to show him that he was not condemned by the bible, nor by his colleagues, despite the discrimination he had experienced.

If you are authentic, you're going to get kicked out. So, I have grown up with this love in the church. All these lovely sermons about love. So, I went to a Baptist college. I finally come out, and I tell my professors. And one of my professors says, I find no word on the bible that either affirms you or negates you. I don't find anything in the bible that speaks to a $20^{\text {th }}$ century gay relationship. I find plenty that speak to a culture 2000 years ago. What they understood as homosexual practices. And it's taboo. I mean picking your nose is taboo. Or, in 
that culture eating a lobster...because it doesn't swim. If you're in the water you're supposed to swim. So, it's on that level, you know. Not supposed to mix your fibers, and nobody gets to wear polyester, and all that sort of stuff.

The biblical text Joshua's professor is referring to is the same Leviticus piece (18:22) that I referred to in opening sentence of this document. His professor is trying to put the quote into historical context, and make the point that culture has changed drastically and what sexuality means to people today is drastically different from what it meant over 2000 years ago. Many modern scholars (r.e. John Boswell) have written on the subject of changing meanings of sexuality and how the historical context of each situation is key to understanding levels of deviance and acceptance.

Ezra discussed her second seminary experience in relation to a previous school where she felt less comfortable. She was able to have her family on campus, and be out at her school, and that was central to her well-being at that stage of her life.

I felt kind of isolated, and Pacific School of Religion just felt better. At that time PSR was the only place where you could live in campus housing with your same gendered partner. That had something kind of cool about it too. I wouldn't have to deal with something as disparaging as being accepted as student and not having my family be accepted. So yeah, I want to PSR. At that time I wasn't attached to a denomination, so I could just work on my actual goal. Most Protestant denominations require either a Master's of Divinity or some equivalent. That's like an academic thing. The denomination that you're a part of nurtures you through the rest of your ordination experience. At that point, it was in seminary that I really left the Presbyterian Church. In fact I had no home team when I was working on the academic credential. It wasn't until I kind of looked around and I found another community that I could be a part of, and that nurtured me really well.

Ezra is one of the three ministers who switched to another denomination than the one they had grown up in once they were ordained. She now works with the UCC, and is the chair of a large organization for queer Christian activism. The community she spoke of 
above is a major piece of why and how she is in the positive and encouraging situation that she has obtained today. Despite some discouragement by her past denomination's stance on sexual minorities, Ezra has managed to use the encouragement that she did find throughout her larger Christian community to attain to a safe and nurturing environment where she can pursue her goals. She is one of the first ministers who helped me realize that my second research question is not necessarily accurate for many of the people I spoke with. Many of these folks do not have trouble maintaining their positions, in the face of some overarching traditions of homophobia, once they find the best path obtain their clergy position. I will discuss this regarding my research question in the findings section of this document.

In his brief reply to my question of seminary encouragement, Reverend Titus noted only encouragement from his colleagues and peers.

They're simply educating you. They were extremely supportive of my call. I felt very affirmed the whole way through. It's a three year process, where you have to jump through a lot of hoops. You have to go back every six months to a year and be re-evaluated. Each time that happened I felt very affirmed, and people obviously seeing a call to ordained ministry for me, and affirming that call as being pretty valid.

By this account, Titus may have had the most affirming and uplifting experience in seminary. He did not mention feeling that his experience would be any different if he were a straight clergy member.

Last only due to sheer uniqueness in comparison to the rest of the cohort of ministers, Reverend Joel, a 57 year old transgendered Methodist minister also noted a very positive experience with his seminary schooling. Joel was not out at the time of ordination, but has since come out to the congregation and has also become an activist for 
transgendered rights within the Methodist faith.

So, I accepted a scholarship to Boston University School of Theology. I went there in 1980, and graduated, and actually did accept ordination. At the time, I had no idea really of the official denominational stance toward gay and lesbian people as clergy. There is a prohibition in what's called Our Book of Discipline, which is like the law book of our denomination that specifically prohibited the ordination of gay and lesbian people as clergy. When I found that I was pretty dismayed.

I included Joel's quote last because it ties into the following section about activist intentions of ministers well. Joel is currently fighting to keep the position as acting minister in a faith that is not yet ordaining out queer clergy. This struggle will be discussed further in the following two sections.

\section{Political Activism (Working Toward Change Inside or Outside the Church)}

The majority of ministers I spoke with mentioned political activism in one form or another as an important element of their lives. Several of them mentioned being part of a "gay rights" activist community, and others a larger Christian community of philanthropic endeavors. Some of this activism manifested in the work queer ministers do in support of gay marriage, and others are activists in ways that do not relate to their own identities at all. These activist identities are often bolstered by the same stalwart support networks that originally helped clergy members obtain their position, and as is evidenced below, they are often intrinsically linked. In essence, this section is filled with quotes of what queer clergy are actively doing about their own persecution, and the persecution and discrimination of others. Activism has given some ministers a reason to enter the clergy and make a difference through their religious authority, and others a justification to stay 
in their clergy position an fight various discriminatory practices.

Making mention of the history of activism in the clergy specifically, Reverend Titus spoke of how the early women's movement for civil rights in the United States had a massive impact on ordination for all minorities. "It was only about 35 years ago that the church started ordaining women to its priesthood, and once that door opened, obviously the other historically marginalized people began to seek acceptance as well (Titus)". A number of ministers remarked on this fact, and felt it important to recall that the push toward ordination for women during the movement in the 1960s plays a huge factor in the ability of queer identified people becoming ordained today. The women's movement opened countless doors, in myriad cultures and occupations in the U.S., and because clergy are in positions of power their path was an important one in this process of civil rights attainment. Reverend Rebecca likely had the most to share regarding female ordination and its links to queer ordination.

The issues of women as clergy have been huge over the years. I envision it as women starting this beach head. There are so many women who started seminary in the 60's and 70's really. Very few of them actually made it to the beach at all. They were either raked out in seminary, or they were not able to get a call. Or they got a call as an assistant and were only able to stand it for a year and they found something else. And then the next wave kept coming. And they established a beach head. So, my position as a woman in the ministry is really built on the countless bodies. The careers of women who have preceded me in past decades. So, to be in a place like Portland, where there are so many women clergy. I have colleagues all over the country who are still the only women in their region. And they make way less than men, and all this stuff. And it's just. They are still fighting the women clergy issues, let alone the lesbian issues. So, literally, there are beach heads that lesbian and gay clergy folks who have preceded me have established. But I would say that really it's the women who have battered down those ramparts and made it possible for lesbian and gay clergy to really find a way. Lesbian and gay clergy really have gotten where we are on the backs of straight women. Who worked so hard to break in. 
One woman clergy member I spoke with has spent the majority of her life fighting for the rights of queer persons, and queer Christians in particular. Mary works both as a Wiccan priestess and MCC minister, and her broad understanding of spirituality has helped her maintain a focus on helping others through the identity crises in their lives.

There were two or three hundred at this rally. There were a lot more people that were driving around and hiding in the bushes that just came to see it. So that was huge. So I thought I have got to come all the way out of the closet about my spirituality, about the goddess, about Christianity, which was hard cause those are really different ideas. Due to the persecution of Wicca by Christianity. So that was a watershed event.

With this statement Mary describes a gay rights rally that she attended in the capital of Idaho where she realized that she needed to come out to all the people in her life. She noticed the double bias against her due to her spiritual connection to Wicca, and her lesbian identity, but she knew that it was necessary in her fight for the rights of all the people she saw being persecuted.

One major theme in every interview related to activism was around the gay marriage debate. Some ministers were actively working to change legislation so that they could legally marry members of their congregations, and others did not directly take up the issue as their own, but were aware and concerned with the effects of such legislation. Mary was very familiar with the marriage topic, and has been performing the symbolic element same sex marriages for quite some time now.

The big issue right now is the whole fight for marriage. All traditions, if your gay or lesbian, or care about justice. We were telling everybody that we would never pursue that. When I was in the early stages, because it was way off the map, not possible. We've come a long way to be talking about it. But it's past time. I've been doing weddings, hand fasting, as they're called in Wiccan tradition. MCC was calling them Holy Unions at first so they wouldn't get in trouble. Since 1995 
I've been doing legal marriages for those who are eligible for it. I do a lot of weddings for male female couples.

For a short while Mary and several other ministers were allowed to wed same sex couples in Portland, and over the course of a couple days they married as many as possible. "When we got the right to marry I think I married 40 people during that small window. I almost didn't have time for my own because I was so busy. So that's an issue, depending on what tradition you're from." Reverend Gabriel works at the Metropolitan Community Church, where many queer congregants (who comprise the majority of the congregation's population) are waiting for the day they can marry their partners as their heterosexual peers have done for years.

We have been doing same sex weddings for forty years. We've just done them. They've never been legal. Probably the first one was our MCC pastor back in the day. That was probably the very first place an MCC same sex wedding was legal. So what's kind of weird is to be a clergy person that...I have done more same sex weddings than opposite sex weddings. I have officiated at more gay weddings than straight weddings. We do more of them than we do opposite sex weddings.

Gabriel is further referring to performing the symbolic piece of marriage, without any form of legal documentation. He has performed more "gay weddings" that "straight weddings" because he works at a church where the majority of the congregants are queer. He also told a story of one couple (whom I will discuss further in a later section) comprised of a transgendered man and his wife. People in the church see them as a straight couple, but Gabriel knows from working with them that they are anything but. In his eyes they are the most queer couple in the church.

Reverend Joshua was unimpressed by the gay marriage debate, and has interestingly stated that he feels that the marriage debate is not a gay issue. Two other 
ministers had similar statements, and Joshua sums up their sentiments up here quite well.

We're not going to be the heterosexuals, we're not going to have the white picket fence, we're not going to have the kids. But, you in my little heart of hearts, I think it's really domesticating the gay movement. So, it's like we're going to be little heteros. But, I am getting a little older and I would like to be able to share all of the things with my partner that everyone else can. But there's this other part of me that says, this is just playing along with the heteros. That's fine for heterosexuals, but I'm just not one of them.

Joshua went on to explain that he feels that the gay marriage debate only became a debate when some conservative people decided that it needed to be. He feels that it is a straight issue, and that the political game of it is being played on the terms of conservative straight people who ultimately have nothing to lose. He is also creating "heteros" as an othered category here. He made a point to say that he respects his heterosexual peers, but that he is not one of them and has no desire to be.

Location of ministry has also been motivated by activist ideologies for some clergy. Reverend Amos selected the place he wanted to worship after seminary according to his beliefs in pacifism and non violence.

This community was very progressive, very active in anti war stuff and tax resistance. So it was a very socially active community in the church where I pastored. There were men who had been C.O.'s in WWII, so their commitment to social justice was very strong. I had a chance during that pastorate, and bought property, with a house and several acres.

Amos then goes on to describe the changing shape of faith traditions, and that the Church of the Brethren, which he belongs to, has become very accepting and open to sexual minorities. He has had no trouble maintaining his position as pastor and feeling encouraged in that position. Amos said that he felt his church's lack of bias toward sexual minorities might be due to the denominations long history of dedication to civil rights and 
compassionate ideologies.

Reverend Gabriel took an activist stance toward his initial decision to become clergy. Recognizing the power imbalance in hierarchical church politics, Gabriel struggled with the idea of becoming a part of that elite power structure, or remaining a lay person and working in the church in other ways. "I felt it harder to really say yes to ordination because I wasn't saying no to every person who was called to ministry. How is my call something that is separate than the rest of them. Working for me without reinforcing all of the crap." By "crap" Gabriel meant the unnecessary level of power he saw given to clergy, that he felt had hurt people in the past and had the potential to do equal harm and good depending on the minister. He saw a heavy level of bureaucracy in many churches that does not exist in his, and is happy to be part of the MCC where he can affect real change within the denomination. Roughly half of the ministers I spoke with expressed a desire to work for churches that had a more bottom up approach to polity, allowing each congregational governing body to decide how its church would be run. Those who did not share this sentiment were part of larger denominations, where more of the decisions made for the church came down from national or international denomination governing bodies.

As a transgendered American Methodist Church (AMC) minister, Reverend Joel has a slightly different angle on how and why to change polity in his faith tradition. The AMC does not ordain lesbian or gay people at this time, but they currently have no rules barring transgendered people from ordination. Joel came out to his congregation two months prior to this interview, and has since taken it upon himself to fight for ordination 
rights of all queer identified persons.

Well there's nothing in there about transgendered people, so they said go ahead. So I said, well, maybe I can do that. I could affect some change while I serve churches. So I made a decision. When I graduated in 1983. I decided, well, at least I can work within the structure of the church for change. And at the same time as a hidden transgendered pastor, expose a lot of people to me. And I hoped that one on one relationships over some years could move people individually to change their attitudes. So, that's what I decided to do. I would feel like, that was over and I should do something else. I hope that answers that part of the question.

Joel works with a highly supportive wife at the church, and is the parent to two fully grown children. In this seemingly normative situation, Joel was never expected to disclose his gender identity. Now that he has come out he has experienced a great deal of political interest and activity surrounding his identity.

I have always wanted to work more with LGBTQ people, and so I have been doing a lot more of that. Last night I spoke with the Portland PFLAG group, and so I was out on a panel at OSU a couple of weeks ago to connect with people. So I have had a lot of opportunities to connect with people, to talk with people. Also, to encourage people not to abandon their faith if they are part of a sexual minority. Because so many people let it all go because they only hear messages of discrimination and hate.

Joel expressed a great deal of concern about how the discrimination from more conservative Christian faith traditions, like his own, can have a detrimental effect on the spiritual freedom of queer Christians. Joel spoke of the many Christians he has known who left the church, left Christianity for other faith traditions, or felt slighted by religion as a whole and shunned by their spiritual understandings and identities. On the specific policies of his denomination, Joel had this to say.

They really are focused on LGBT people, and I'm pretty sure that they are going to try and pass legislation in the next conference to specifically include transgendered people. So, part of my reason for coming out now is that I have three years to be public and vocal. And to try to stand against those attempts, and also to have that other language removed from the Book of Discipline. It comes 
up at every conference, and has since it was put in the book in 1978. So I stuck it out for that purpose, that we can change the Book of Discipline. Over the years I have lost a lot of my closest colleagues, who have said that enough is enough. They have moved on to more progressive denominations. But I have stayed, and I am going to stay until I see what happens at our next general conference.

Joel is an activist working toward the inclusion and rights of all minorities in the church.

With a clear understanding of the issues in the Methodist faith, Joel expressed a deep obligation to change these denominational biases at their root. This drive toward equality is a large element keeping Joel in the Methodist tradition, rather than moving on to a more open and affirming tradition. Joel's was one of the only stories of a person facing difficulty in maintaining their position with their church.

As I mentioned in the methods section, I asked each participant what they felt would be interesting or useful to add to my study, or to use for future research. Four different ministers informed me that they would be interested in a study on whether queer clergy fee that they have something special to add to their position, or a special quality of understanding of Christianity that is directly because of their identity. In an activist sense this was linked to the ways queer clergy could change the face of Christianity to a more accepting one, or the ways they might be able to mentor and encourage other queer Christians that their straight colleagues could not. Gabriel mentioned a sense that he may have a different lens through which to examine the way Christianity is understood than other people, and that this was of seeing things is related to his identity.

It's not just a perspective that gets included among many. But it's, I am a gay man, looking at scripture, preaching to mostly queer people. So there are things that we are going to notice or talk about, that may not be noticed or talked about in your open and affirming UCC, because our lived experience is different. We hear and proclaim the good news in a way that is queer. 
These and other ideas shared at the end of each interview, as well as in the future research section of this document. The focus of this research was to privilege the words of clergy members, and by adding these suggestions to following research.

Some clergy were lead into ministry directly through activism, and all of those that I spoke with have maintained their active political behaviors. Working as a minister is a full time job, and with additional activist work, many ministers are spending every hour they are awake working for the good of others. Reverend Rebecca has been an activist from a very young age, and continues to work for the rights of disadvantaged people endeavors in her job and everyday life.

I come from an activist family. My mother was very active in peace and justice work, and I was very active in peace and justice work in high school. Moved to Portland in 1972, and came out. And, was living life and doing things. Involved in nuclear arms stuff. Was involved in the women's league for peace and freedom. At one point was involved in the Washington DC women's book store. volunteered with the women's book store here.

Rebecca has traveled all over the United States protesting and rallying in support of peace and social justice. Throughout her activist career she attended to several marches on Washington, chanting and leading groups in support of freedom and equality. It was through these experiences that Rebecca began to sense her call to ministry.

So, in 1987, I went to the first national Lesbian and Gay march on Washington. Which was really quite a great time. I went two years later as well. As I was standing in the ellipse there at the white house, there where the Oregon contingent was slated to step off. It occurred to me that I had been standing in virtually the same place over the years. In the various moratorium marches against the Vietnam war, when I was in college. I was in Washington DC when Martin Luther King came to town in 1963. I was there with Jobs With Justice, the ERA. All these different demonstrations for all these different things. Now here I was with my GLBT brothers and sisters. And it suddenly occurred to me that it was all the same struggle. It just has different names. And, it's all about self determination and justice, and being able to live your life. Security and joy. It was one of those 
moments where I felt like I had been doing all this peace work and all this justice work, and all this community organizing. And all this lesbian and gay stuff. And it occurred to me that what I really wanted to do was to do something that would begin to pull it all together for me.

Here, Rebecca regards her clergy experiences as an activist role in its self. She noted that this helping role has given her great fulfillment and purpose in her life. Much of this connection came to Rebecca through some activist work she did in South America as a youth. She found that activism and Christianity were directly linked in many other parts of the world.

When I got to Nicaragua, there were pictures, there were huge murals. All these murals everywhere, with Jesus as a compasino, or doctor or teacher. I didn't understand what that was about. Nobody in all the training we got ever mentioned the word "Liberation Theology". I don't know if you're familiar with LT, it's a...it comes out of Central and Latin America. Radical priests and nuns down there, who had this crazy idea that god loves poor people. As much as god loves rich people. And that the poor had the right to security and healthcare and education. And indeed, that god has, in the words a Preferential Option for the Poor. People took it to heart. The idea that Jesus could be on their side. And in a progressive world, nobody talks about religion. It's way cooler to be Jewish or Buddhist, than it is to be Christian.

Although Rebecca mentions the less than favorable status of Christianity in U.S. activist culture she also admitted that there was no other place for her than her church. Liberation Theology is highly important to the ways Rebecca maintains her congregation, and formulates her ideologies surrounding her Christian identity.

Reverend Ezra has taken her activist identity to the forefront of her full time occupation. She is the head of the Community of Welcoming Congregations organization (CWC) in Portland, and was seeking ordination through the UCC at the time of this interview. Her work with the CWC has helped many congregation learn what they can do to become more open and affirming to new and returning members. Ezra was also 
actively involved in creating awareness around several bills at the federal level at the time of our interview.

So there are two bills right now. There's a hate crimes bill, that they're calling the Mathew Shepard Act. Which includes gender identity. The other is a federal employment gender non-discrimination act, which includes gender identity as part of the reason that you would be able to hire a person based on gender identity. Those two issues are huge. Religious communities tend to be way under resourced around those two issues. Anything you ask folks around those two would be really pertinent to where the welcoming church is right now. And what's Important about having all the welcoming churches together.

Lastly, Ezra shared a narrative about a protest she was a part of in downtown Portland.

This protest came in the wake of Measure 9 in Oregon, which would have made it mandatory for public school teachers to tell their students that any non-heterosexual relations were abnormal and wrong. The power of this measure was tied to state funding, and would have included punishment for instructors who were found teaching anything but heterosexual sex education.

We owned a city block in downtown PDX, and we wrapped a ribbon around it, and declared it a hate-free zone. And that not only brought a number of queer people, but just liberal minded folks, into the church. So, the church was ready to call a queer minister I think at that point. I am almost ambivalent about the whole gay marriage issue. First of all I don't think it was our issue. I don't think we came up with that issue. I think the right wing came up with that issue and we had to respond to it. So, we're playing that game on their field. So, I feel like that's annoying. Waste of energy and money that could be better spent. That said. Dianna and I got married fourteen years ago. In a church. We had a clergy person presiding. It's a marriage. We got married. It's not like we need to call it something else. Of course we should be allowed to be married, but is it my issue...no. I appreciate the people who do feel that it is their issue. That's great, but it's not what turns my crank. It's not what gets my blood going. And my church is, we were formed as an open and affirming church. So, if someone calls up and says "can we send someone over to speak to your church/ I answer, you are wasting your time here. There is no person in this church that would vote against that. Don't waste your time here. In terms of that, it's not a cause I will jump to. I will support it, but it's not where I will be putting my energy. 
This lack of interest in the marriage debate was shared nearly equally to the number of times the debate its self was presented. Many ministers stated knowing that it was a hot activist issue, but that the people in their congregations already believe same sex marriage is a great idea, and it would be a waste of energy to discuss this with them. Ezra spoke of many other activist issues taken up by her church, including housing for the city's homeless, and peace efforts for various warring nations around the globe.

\section{Denominational Policies and Practices (Elements of specific denominations that have} positive or negative influences)

Denominational policies and practices are a great source of encouragement for many of the ministers who participated in this study. Over half of this group was forced to change the denomination they worked and/or worshiped at after they came out to everyone in their lives and realized that their denomination would no longer accept them. For some, the choice of denomination was not linked to their identity, but to their philosophies of religion and spirituality. For four of the ministers I worked with a "church hop" (denomination switch) was not necessary, as they were either accepted by the tradition they had grown up in, or chose to remain in a less affirming tradition and fight for change.

\section{Switched Denominations}

Reverend Titus found his way to the Episcopalian church through a great deal of searching and theological exploration. He was born in the Catholic faith, and found it important to maintain a similar religious practice in his adult life. After spending a good 
majority of his adult life in a corporate desk job Titus decided that he needed a spiritual

component to his daily work load.

The blending of the two institutions, in terms of liturgical and sacramental expression was extremely important to me. I don't feel, I wouldn't have become ordained in a religious institution that didn't have a sacramental element to it. I was talking with the priest from the church my partner and I were attending, about my options after I left this corporation. He said, 'well, I don't know if god has to take a two by four and knock you over the head with it, but I think you should go back to seminary school.' So at the time, when I moved out here, in the Episcopal church, the level of liberalism. The level of acceptance of gays and lesbians, has a lot to do with where you are in the country. Depends on the diocese. When I found an institution that validated who I was simply because of who I was, that was very profound for me. For a church that, in its very foundational documents, says that one of the promises that we make when we're baptized is to respect the dignity of every human being. Well, to respect the dignity of every human being, means every human being. So when I saw that I knew that I could identify with that institutional church. That was a church I could serve in the way that I felt God had always called me.

Titus found a denomination that was aligned with his theological leanings and his identity simultaneously. He was able to be out and partnered in this institution, and found nothing but encouragement in the congregational polity style. Most of the decisions in his faith tradition are made at a level that he and his colleagues have a direct affect on, and therefore they can make their church what it needs to be for them.

Reverend Mary also expressed full encouragement upon switching denominations in her adult life. Mary remains a member of more than one faith tradition, or spiritual language as she prefers to call it, and has found good qualities in all of them. "Then, when I first came to MCC, what I valued there was the diversity of the people. At the time Wiccan circles were not so diverse, because at the time it was word of mouth." Mary also noted that Wiccan traditions are a further persecuted form of spirituality, and have not spread to many different groups of people as a result. With its essentialist inclusion 
policies, the MCC where she now works has provided a more diverse demographic that Mary was looking for in her spiritual community.

One minister in the category of people who changed denominations upon, or in order to, become ordained was Reverend Rebecca. Based on the encouragement of friends and family, Reverend Rebecca formed her own church that is now a part of the United Church of Christ denomination. Rebecca was not able to reach ordination in her former Presbyterian tradition, and had nearly given up on the task of ordination as it did not seem as if her identity and faith community could align. "If not the first, I was close to the first out lesbian/gay person in the Presbyterian church to become a candidate for the ministry. You could do that, but you couldn't get further than that. So I spent the next few years defending my candidacy. Then eventually Bridgeport was born." Groups of friends would consistently remind Rebecca of her call to the ministry, in an attempt to get her to start a church of her own. These were queer and straight friends who felt that Rebecca had a gift to teach people about Christianity.

"And finally, the hundredth monkey climbed up on my back, and I said fine. I will do it, but I can only do it part time, because I work all the time. I gathered the dozen people into the living room. People who said that they would help whenever I decided to take that step. And I said, okay let's do it. They were the people who said they would support me when I finally decided to do it, and gave me the wherewithal to go about doing it. So, I sat down and wrote a letter. Sent out a hundred and twenty five letters to people. From people who said, when you gonna, to people who didn't get totally disgusted when I told them I was going to seminary. Back in 1998, we said we're going to start a church. It's not going to be a fellowship, not going to be a community. It's going to be a church. We're going to meet at 10:30 on Sunday morning. And we're going to call it...Bridgeport Community Church. Because Portland's full of bridges and ports, and a port is where you start a journey and you end a journey. You seek comfort along the way. And bridges connect people and ideas. This was before the brewery even, I think. And certainly the shopping center out there in SW. So, we sent these letters out and said, we're going to have our first service on May $30^{\text {th }}$ of 1998 at the ministry 
center at PSU.

The church is housed in a former Presbyterian building today, and every seat in the pews is filled on Sunday mornings. Rebecca has been highly successful creating a faith community with her new denomination, and is promoted to stay at her church through the political activity of her members as well as her ability to keep the church working for the needs of its members.

Reverend Ezra also experienced reluctance to her call to ministry, and sought council in order to find out what path might be best for her. Raised Presbyterian, Ezra mentioned being hurt by her denominations stance on queer identity, and was pushed away from church entirely for part of her life.

And I was reluctant to come back to the church because my experience was so painful. I didn't really want to do that. So I entered spiritual direction, for about a year my spiritual director and I discussed what my call meant, what the challenges for me are. When I found the UCC, several things let me know that this was a call for me. One was a connection that I made in the first week of attending the UCC congregation we are at now.

Ezra went on to discuss the importance of her new denomination, and the ways she now understands Christianity as an open and accepting spiritual culture. Upon joining the UCC she realized that her sexuality did not have $\mathrm{t}$ be an issue at her church and that she could worship in peace, just as her straight fellow congregants had done at her former church.

\section{Remained in Previous Denomination}

Episcopalian minister, Reverend Ruth, also found a great deal of encouragement through the policies and practices of her denomination. She was not necessarily searching for a path to ordination, but her involvement in the church throughout her adult life led 
her to the conversations that would create that desire. Regarding a comment from one of her early ministers, Ruth added:

"He said, I want you to know, our bishop is looking for partnered gays and lesbians to ordain to the priesthood. It was a conscious effort on his part. I didn't feel called at that time, but several friends who were gay and lesbian did. So I told them, don't let your local priest hold you back. So that was in the back of my mind. I felt that I would have had his support once I got there. But knowing me I probably would have tried to push through."

Ruth was directly pushed through, and maintained her denominational affiliation with this encouragement. The Episcopalian Church was one of the first denominations in the U.S. to ordain women, and subsequently to ordain queer clergy as well. Ruth was fortunate that her religious views and understandings were fostered in a denomination that affirms her identity as well as her call to ministry.

Regarding the specific policy measures and ways of governing by her denomination, Ruth had only good things to say. This quote is yet another example of the positive emphasis many clergy members put on congregation level policy creation that is not dictated by the national church body.

Many churches have volumes of rules. So the things that I would mention for the Episcopal church, that are broader than me. And maybe broader than Oregon, are (references Gene Robinson, first ordained out clergy in 2004, here) the acceptance, culturally, across the country of gays and lesbians. Policy is set in the summer, we set two very important policies. One to reiterate what our cannons say about sexual orientation not being an impediment to ordination at any level. Which was sort of like saying to the Anglican communion, you can no longer force us to violate our own cannons. So, that's been going on. And we're not alone. So, but there are congregations that are not comfortable with it, and it is something that might lead someone to leave one congregation for another one, but stay within the church. Things are deliberately worded to make that a smooth process. One of the tenets of the Episcopal church is that we come together to worship. We come together to share the Eucharist. We don't need to agree doctrinally to do that. It's really living our faith. The doctrine behind the living varies widely. 
Here, Ruth gets at an issue addressed by many participants about the desire to diminish the importance of their sexuality in their spiritual and secular lives. Every person I worked with, including those who have dedicated their lives to the struggle for civil rights of queer identified people, made some mention about not wanting their minority identity to be at the forefront of who they are. An ability to feel normal about their minority sexual or gender identity was an overarching theme that arose, and was celebrated by clergy who worked in open and affirming congregations. This often came up in interviews similarly to the way Gabriel put it, "I don't always want to be the gay priest. Sometimes I just want to be regarded as a minister like all of my heterosexual colleagues".

Ruth made a point concerning the repercussions of this identity silencing as well. This does not necessarily have to do with specific denominations, rather I would like to make a connection to the previous section within these . She noted that she has been searching for better ways to let people know that she is a lesbian, particularly when she is at a new church and people will otherwise regard her as a straight person. She feels that many members of clergy appear to be conservative people, and their sexuality and gendered identity will be assumed normative (straight) if not otherwise indicated.

How do they know? That I'm a lesbian. I don't walk up to someone and say "hi, my name is Caroline and I'm a lesbian", I walk up to someone and say "my name is Caroline and I'm a priest, and I've just come to be a part of this congregation". And I don't think, from talking to other people, I don't think I'm alone. I think that issue, or that challenge, I think there's a challenge there in terms of identity. And I think that challenge is real, and I think the other part of the identity challenge is...well it's the challenge of how to handle it. And how to handle it in a way that's honest, genuine, but doesn't distort the call. My call. I do know priest who feel very clearly, that right up front, one of the two most important things about their 
priesthood is that they're gay or lesbian. So they're ministering to those folks, and they're out there. So you learn about that in the second or third sentence. And it's really not true for me. It's a vital and important part of who i am. But it's not, I mean I have friends who say "I don't care who you sleep with. Straight friends. And I say well that's nice. But in our society you assume I sleep with somebody that's straight.

Ruth, and others, feel that it is important to have their identity recognized, yet not accentuated more than any other persons'. This creates an interesting sort of paradox, and will be further outlined in the following discussion section.

Reverend Luke was also able to remain in the denomination he had attended prior to his ordination. He mentioned discovering the existing biases toward queer Christians in other faiths while in seminary, as he could think of none in his own denomination. When I asked Reverend Luke if he had ever felt the need to change his denominational affiliation, he had this to say:

No. I was a UU going into seminary, and so that did not change, and was in fact likely enhanced. One of the things I discovered in seminary was, um, a greater degree of homophobia in other denominations, and I think the UU have been pretty, that's one of the areas that they've succeeded. We have openly gay clergy in some of our largest churches, and so, um, while I don't think we've completely transcended those barriers, I think we've done, maybe a lot better than other denominations. And everybody is there because everybody is there. It's not a ghetto church for anybody. It isn't special that we have our gays, or isn't special that we have our straights. So, we're very progressive. The byline has always been "we're progressive political people exploring our Christian faith. There's no question, I don't have to apologize for being against the wars. It's right out there. And we have incredible music, and it's a very lively experience at church. It is so not stuffy. It's not a "big church". We're self supporting, and I work full time. It's been a blessing for me.

Luke's excitement surrounding his denominations policies and practices throughout the Unitarian faith tradition create a very positive picture of just how open and affirming a faith tradition can become. He expressed a desire to share this open and affirming model 
with the polity members of other denominations, in an effort to help all faiths become institutions of equality and encouragement for their members. Luke has found full backing of his non-religious progressive ideologies through his church as well, and noted engendering the same in his congregants. The Unitarian Church, primarily comprised of ex-members of mainstream Christian faiths, is a non-doctrinal denomination. This means that there is no specific god or creed that anyone must believe nor adhere to in order to belong to the church. This may make it problematic to compare Luke's experience to those of others, and I will discuss this in the section titled limitations and future research.

\section{Endurance for Change}

Only one of the ministers I spoke with was in a position where their denomination would not accept them, but they planned to stick around as long as possible to try and erase the barriers they faced. Nearly all other participants expressed a desire to do so, but realized that their ordination would never take place if they did not switch to a more accepting denomination. Luke, the transgendered Methodist minister who participated in this study came out to his congregation and denomination the summer prior to my interviews (which were conducted in the fall of that same year) and was making every effort to change the course of Methodist faith tradition for gendered and sexual minorities. I am not making the claim that Luke is the only minister that had the conviction to stay in a non-affirming church and work for change. Luke was the only person who came out in a non-affirming tradition after they had been ordained. All others came out before or during seminary, and quickly realized that they would never be 
ordained by their denomination.

Reverend Luke is working for equality throughout the Methodist tradition, and had this to say about the youth in that faith:

One of the most painful things I talk about, especially with younger people, is their sense of isolation from any spiritual community or connection. So I think it's really encouraging that there are groups of people that want to get together and change those policies and attitudes that are so prevalent out there in the media.

Luke felt that young people are fed ideas of homophobia through consumerist channels that damage the ways they are able to interact with other people. A desire to work with different organizations to educate members about these issues was not unique to Luke's experience, but the context of the Methodist faith certainly was.

\section{Homophobia (Internal \& External)}

A great number of people in the U.S. are brought to places of worship by their parents, and taught the tenets of religious texts, stories and songs according to their faith traditions ways of interpreting such artifacts. For those in more conservative traditions (Roman Catholic and Presbyterian for example) some of those tenets create a perception of deviance surrounding any sexual behaviors or thoughts other than those understood to be straight (heterosexual). This sort of teaching can cause a great deal of self hatred and cognitive dissonance (see footnote) for congregants who identify as anything outside the acute norm. Reverend Luke mentioned an interesting functional perspective of the creation of deviant minorities when he said, "I think in a lot of religion there is this need to have the other, and gay folks are this convenient other. And I think like a lot of things it's changing. With young people, the level of acceptance is much greater. But yeah, it 
makes me sad." We did not get a chance to delve into exactly why Luke feels religions require a deviant scapegoat, although his point is interesting in the context of this set of coded statements.

This section consists of shared stories of homophobia experienced by the clergy members I worked with that I have coded into three different categories, including: internal, external related to church or denomination, and external related to the larger culture or environment. Internal homophobia codes were determined by clergy members stating that they had internal or psychological conflicts with their sexual or gendered identity based on what they had learned about gender and sexual deviance throughout their spiritual lives. External homophobia, for the purposes of this research, refers to any actions, teachings, or sentiments that negatively portray the behaviors, feelings or identity of queer identified persons. Clergy members made statements concerning external homophobic action and sentiment from both church and denominational origins, as well as more broad homophobia that they experienced in larger culture. Homophobia from the greater culture can be experienced by any queer identified person who belongs to a religious institution or not and therefore was mentioned less due to the way the question was addressed. Many clergy members focused on homophobia from their denomination and church specifically, as this was the focus of the study. In future studies I would like to further explore the effects of direct homophobia from peers and colleagues, verses a more ubiquitous homophobia of mainstream western culture. For this study these two categories will remain separate, and be used to illustrate the different ways clergy experience homophobia in their occupation. 


\section{Internalized Homophobia}

Reverend Amos noticed his attraction to other men at a very young age, and mentions knowing that this understanding of his desires was problematic before he was old enough to recognize himself as a sexual being. I "actually became aware of myself as a homosexual at age eleven. I was first aware of myself as a sexual being. I found myself attracted to male peers and not female peers. I was scared, but not terrified. It was traumatic, but I thought it was manageable." This new understanding of himself lead Amos to question his place in the world, and why he felt different about attraction than he had been taught was normal. Reverend Gabriel also had a very negative experience with his initial understanding of sexuality.

I had a very early awareness of being gay. I never had any same sex sexual experience until my very late twenties, but I had long-term recognition of my sexuality. And I was also deeply involved in the church. While I didn't grow up with any conservative church background, and through the church I got the messages that, Gay wasn't okay. So I did, I had that classic struggle. I call it the sea saw. When I started to come out I began to affirm. Okay, I am gay. Oh my god, it took me hours to say the word. It was something I had known all my life, and to say it. In a safe place. It was very difficult. But true. And, so much of that was wrapped up in the deliberate messages that were the only ones I had heard. I remember, I was a senior in college. I had actually been out for three years. I was in college. I had not yet been out to my family, but I had started to come out of the closet. I was sitting in class, and it was the very first time I heard someone who knew about Christianity say, just as an offhand comment, the Bible doesn't condemn Christianity. I just thought a bomb went off in my head. I said, WHAT? I couldn't believe that someone who knew a lot more about the bible than anyone in the class. He was smart and spiritual, and all that stuff. He wouldn't just say that if he didn't have a really reason to let us know that was true. Even though I had been out for a few years, it felt like a bomb went off. I couldn't believe my ears. My whole world view was shattered. Yeah, so the homophobia was so deeply entrenched that it was the only negative Christian view that I knew. Until that time. Even though I was self aware that I was gay, I knew...

The very fact that it took Gabriel hours to say to himself that he was gay is a great 
example of the power if internalized homophobia. He had been taught by his church and peers that being gay was not okay, and the stigma attached to what he now knew or himself was frightening. Gabriel mentioned that it took him several years until he came to the conclusion that what people had interpreted from biblical texts to be condemning sexuality was not scripture that was intended to be taken literally. In fact, what was being quoted was not scripture that was necessarily about sexuality at all. Many of the ministers I spoke with mentioned a watershed event, such as this classroom experience for Gabriel, that helped them to realize the faults present in all these biases.

A hand full of ministers also mentioned the importance of the essential good and acceptance within Christianity, and felt that there was no way that God would take issue with their sexuality. Reverend Ezra put this same sentiment quite succinctly, "The point of religion is to make us more compassionate. If you become more compassionate, then religion did its job. You are accepted, exactly as you are. And if you want to use religious language, god is love, and all who know love know god." This is a sentiment that was present in nearly every piece of this research, but was particularly mentioned in relation to members realizing that their religion was not against them, rather that some people had misinterpreted it for their own purposes.

Titus also mentioned having experienced internal struggles with homophobia, which was tied to his adolescent affiliation with the Roman Catholic Church. Catholicism was touted as one of the most conservative, and least open and affirming, of all the denominations people spoke of. For Titus, the negative view of his sexuality from the church caused him a great deal of grief as a youth, and eventually made him switch to the 
Episcopalian faith.

I was 19 years old, and struggling with issues around human sexuality and my own identity. And, having an inbred sense of that identity being sinful, I figured that the priesthood was a good way to not have to deal with sex at all. Then when I got to seminary I found out that that wasn't necessarily the case. But, I still wasn't ready to identify as a sexual human being at all. Plus, in my own inner struggle from my identity, I was sublimating a lot of what was going on for me. So I got into a sort of psychological crisis and decided that I wasn't going to be able to pursue ordination as a Roman Catholic priest. So, then I wondered around for a while, many years, un-churched. Then I found Dignity, which is an organization for gay and lesbian Roman Catholics. By the time I found out, I had come out, and was pretty comfortable with my sexuality. So I kind of tried to go back into the church, through that door.

Similar to the U.S. military, the Roman Catholic Church has a general "don't ask don't tell" policy, that essentially assumes that if a person is not sexually active (i.e. celibate) then they can be classified as straight. Titus, among others, criticized this essentialist view of sexuality as a mere set of physical (and easily categorized) actions. This silencing was not satisfactory for many clergy members, including Titus, and they chose to move to an environment that was more accepting of all of their identities. This was often noted by clergy members in interviews with the phrase "I was finally able to bring all of myself to church", followed by a great deal of positive sentiment regarding their new found openness.

With regard to the larger queer community, Titus alluded to a sentiment of confusion surrounding his decision to become ordained. He, and other ministers, explained a sentiment from the larger queer community that made it seem as if they had betrayed their people. The sentiment could be paraphrased with a statement such as this: if Christians have made you feel negative about being gay, why would you want to join them and be ordained? Or, as Titus more eloquently states it below. 
How do I integrate myself into a community that has been so historically hurt by the church? Why would I choose to associate with an institution that has been so historically homophobic. So it kind of cuts me off at the knees as far as ability to spread the good news about the institution I'm a part of. Which really is looking to become more accepting of the gay community. And I get looked at like, why do you even bother? I must say, I do it myself. Especially when I see gay men who identify as Roman Catholic. Are you crazy. Ultimately, there's something that's still attracting them there.

Titus, interestingly, returns to make the same statement himself, and seemingly realizes that there is a draw to a specific faith for everyone, regardless of what the tenets of that faith may be. His mention of an apparent inability to inform others in the queer community of what he sees as virtues in his religious institution is also a good illustration of the high level of homophobia associated with Christianity. This piece presents yet another interesting future study that could include the perceived levels of homophobia from different institutions throughout western culture (including government, schools, churches, etcetera) as experienced by queer and straight identified persons. This is simply one of the myriad possible research inquiries that have come out of this study.

A number of the ministers I interviewed spoke of a great deal of internal struggle with their ability to even consider themselves Christian after coming out to themselves, due to the great prevalence of homophobic rhetoric in a great number of their religious institutions. Luke put this sentiment quite clearly in his following statement.

Being in the closet, the worst thing about it is I think the self hatred. That can build up, and being a minister is about, loving people for who they are, and calling a fullness of being in them that, you know, celebrating them for who they are. If I can't celebrate that in myself then it's hard to help someone else, so it's huge. And yet that was a huge part of the journey and the process, was coming to embrace myself for who I was.

Luke's note about feeling that you are whole and able to help others feel the same was 
mentioned in nearly every interview I conducted. This also harkens back to the sentiments expressed by nearly everyone concerning bringing all of themselves to church. There is a clear sense that ministers felt that to remain closeted would somehow cheat themselves and their faith communities out of a piece of what they have to offer as whole human beings. This focus on wholeness is also related to what several ministers expressed as a gift that queer identified people might bring to the church through their different perspectives of literature and theology. This will be further fleshed out in the following discussion section. To reiterate the emphasis on wholeness of being that is sensed through coming out, here is an eloquently stated quote from reverend Ruth.

I think that a fundamental piece of that was the sense that I owned all I was. A piece of god that passed all understanding. A phrase that you hear and use all the time, in blessings. I just realized that there had been various kinds of wars going on inside of me, and anxieties of one sort or another, and I just could not put my finger on them. And I'm still not sure about. Accept that I think they rose out of my internal struggles. And I say that because they went away as soon as I embraced who I am. Who god had made me. And that's my theology of creation. It was awesome.

I have written here, at length, about the internalized understandings and struggles surrounding homophobia that clergy members once held in their minds, and often judged themselves by. All of the ministers I interviewed eventually overcame their internal homophobia, and came to better accept themselves as they are today. A couple participants mentioned never feeling that they experienced internal homophobia, and that they were fortunate to be raised in an environment that allowed them to be exactly who they felt they were from their very first memories. However, for the majority of my interviewees, homophobia was reinforced both from within their own minds (via their socialization) and from their churches and larger communities. 
External Homophobia (Related to Church, Denomination, Theology, or Christianity)

In a discussion with one of the clergy members at his seminary, Reverend Amos found a great deal of encouragement related to the changing face of homophobia in his

denomination. This particular minister was not able to come out during his life time, and found a cryptic way of saying so.

He had a lovely wife and children, and he and his wife were very happy. I idealized him, in a way I wanted to grow up and be him. And, he said 'you have more options than I had in my day'. Which was his way of saying, so am I. And it was just a wonderful connection. 'Growing up in the forties, I didn't have theses kind of options. I worked, I got married, had kids, and that's my life. I didn't get to do a lot of things I might have liked to have done'. So, he didn't get to say any of that. He could just say, 'you have more options than I had in my day'. And it was so beautiful, and so meaningful.

Amos has been a minister the Church of the Brethren for many years now, but he did experience a great deal of homophobia from his former religious experience. He decided at a very young age to suppress his sexuality and live a life that appeared more "normal". Amos was married while in college, and had children with his now ex-wife, Eileen. He had been out to his wife from the beginning, but felt that he would never be able to be partnered with another man and maintain the rest of his life the way he had been. The two separated after Amos realized that he could no longer live with part of his identity hidden from himself and others. Today he and Eileen work side by side in the same church, and have continued a healthy friendship.

As one of the many ministers who were forced to switch denominations, Reverend Rebecca has a somewhat Freudian look at the way some ministers take on their call. 
It's folks who get confused into thinking it's about them. They are the ones who hit the walls way more. I mean, I had to leave the Presbyterian Church, it's a fact. It's not because I didn't love them. Or they didn't love me. The denomination thing was just a silly road block that I could either keep running into and not do my ministry. or just say 'I'm doing my ministry'. So, as Lesbian and Gay people we really are just like straight folks. We can't not be. This is a stupid time sucking job. You are in it. You have to be available 24/7. You have to find time to talk to people about all kinds of crazy things. It's a huge job. Those of us that do it would rather not do anything else. So, in a lot of ways, as a lesbian person I am in a lot of ways no different than my straight companions.

Rebecca's and her colleagues are enduring substantial struggle trying to maintain their lives alongside an extremely demanding occupation. She feels that it is necessary to take the personal issues out of the equation, and work for the people she feels called to serve. Reverend Ezra, also a former Presbyterian, makes a similar nod to her call being bigger than herself. Her addition here is important to get a glimpse of the importance gender and sexuality hold with regard to scripture interpretation and theology.

I don't feel that I could separate that. I teach all the time that our sexuality and spirituality are inextricably interconnected. So, internally it's not a question of more or less or good or bad, it just is. So it becomes an issue in the world where people jut don't understand or are ignorant. Or there is actual prohibition against being "unrepentant, self avowed, practicing homosexuals. That's where it becomes an issue. So internally, will my being a lesbian affect how I know god, probably not. Does it affect how I read scripture? Absolutely. Does it affect, as a woman, does it affect the way I read sacred texts that almost exclusively describe people thinking of god as male? Your lens that you look at your sacred texts or you look at the world does have some impact. But not with my own connections, with god. It's not even really relevant. Instead she had to overcome her connection to her former homophobic denomination, and move on to one that allows her to conduct her ministry as she the person truly is.

Ezra made this statement directly after explaining how and why she left the Presbyterian

Church. She felt it important that I understand how important gender and sexual identities are in her spiritual life, and that they are not simply elements of her that she could hide or negate in order to stay with the same denomination. Her quote here also illuminates her 
sentiment toward the idea that queer identity bares some difference on the way that ministers understand spirituality, and that the unique interpretations queer ministers convey are valuable.

Reverend Titus, a former Catholic who switched to the Episcopalian faith in order to remain out and open in his personal life, experienced some institutional homophobia in his new "open and affirming" denomination as well. When I asked him about the ordination policies of the Episcopalian church he said:

Depends on the diocese. This diocese did not have a reputation of being extremely open or accepting of gay people here. In fact I heard that the bishop had allowed an openly gay man to be ordained, but he wouldn't do the ordination himself. $\mathrm{He}$ wouldn't lay the hands on and do it. He invited another bishop in to do that. So I knew there were issues around gay and lesbian people in this diocese.

This is particularly interesting given the location of the dioceses that Titus was applying for ordination with. Many of the ministers I worked with felt that Portland was a particularly liberal geographical location, and that their job would not likely exist in any other place. For Titus, the location of his diocese spanned far beyond the city of Portland, and the polity that determined the region's stance on ordination was not located within this liberal pocket. He mentioned that Episcopalian churches could be very liberal or conservative depending on their location and the moral stance of the congregants who attended churches within the diocese. In the future I would like to add a geographical component to this research project in order to compare differences between more and less liberal regions of the U.S. This might be an excellent co-study to conduct with someone working in human geography, and is something I plan to investigate during my extension of this inquiry. 
With likely the most lengthy and tumultuous seminary experience, Reverend

Joshua told a story of his lover who visited him during his freshman year at Princeton.

Homophobia in Joshua's experience came not only from his peers and fellow classmen, but from Princeton University itself.

He spent the night. That group went to the administration and said...we've got this fagot on our floor. We've got to get rid of him. And in the Presbyterian Church, things have changed. But in 1986, the Presbyterians had a pretty strong position. They didn't ordain gays and lesbians. The president of Princeton Seminary was very open about saying that if they ever found out that anyone was gay, during the admission process, they would of course not admit them, because the mission of the university was to produce ministers. And if you're gay you can never be a minister.

The amount and severity of homophobia and discrimination Joshua dealt with throughout seminary has played a large role in shaping the way he interacts with fellow Christians who identify as straight today. This was true for many participants, but none to the level that Joshua mentioned.

I would like to close this section with a more positive story. Reverend Ezra had a very uplifting thought to add about the way an open and affirming denomination could be nurturing and bolster the spiritual needs of its community.

And everybody is there because everybody is there. It's not a ghetto church for anybody. It isn't special that we have our gays, or isn't special that we have our straights. So, we're very progressive. The byline has always been "we're progressive political people exploring our Christian faith. There's no question, I don't have to apologize for being against the wars. It's right out there. And we have incredible music, and it's a very lively experience at church. It is so not stuffy. It's not a "big church". We're self supporting, and I work full time. It's been a blessing for me.

She wanted to point out in her interview that her church was not merely "the gay church" nor was it entirely like any other church. To her, it is a place where people can come to 
worship together, regardless of any of their identities, and share their experiences in a positive environment. After having to switch her denomination, Ezra has nothing but good things to report concerning her denomination and her religious experience.

External Homophobia (From Larger Culture)

Although this study focused on encouragement and barriers to ordination for queer identified people, some of the clergy members I spoke with found it pertinent to discus elements of the larger culture that affected their decision. I will not go on at length about this, as this should be saved for a study with that focus in mind, but I would like to give space for a few of those quotes that had a clear affect on ordination. There were further quotes relating to this section, but I will only be including those that directly related to clergies' occupational experiences. Reverend Luke has struggled with homophobia from others throughout his life, and even in his open and affirming congregation he has a consistent fear of the intentions of a homophobic society outside his congregation.

I think we're privileged to be in an open and accepting congregation. I don't think a whole lot about it, because my congregation accepts me. You know, I'm out in sermons, but I don't talk about being gay in every sermon. It's like, when it comes up it comes up. There are ways that I'm aware of the homophobia in the larger culture. Um, more like, like I'm really sensitive around kids not to do anything that may be questioned. So those are the times when I'm more kind of cautious. And again that's not because of anything I've got from the congregation. I'm aware of not wanting to do anything that could be seen as inappropriate or, um. And I think that that, just being aware of the stereotypes that are out there and not wanting in any way indicate those. Stereotypes. Um, I get nervous about the violence in the larger culture, and I think homophobia is one of the last acceptable prejudices, and I get nervous about somebody coming into the church on Sunday with a gun. And you know, I don't wake up thinking about it that, and yet that's something that's always sort of there in the back of my mind. We're an urban 
church, and we're pretty out there in our beliefs. Those kind of things are in the back of my mind. So, I think it's sad that mainstream religion is so divided over this issue. There was just a piece in the paper this morning about, a group of Lutherans breaking off from the Lutheran Body over gay ordination.

Here, Luke makes an interesting point about the perception of queer identified people regarding children. He later said that there is a strange misconception that gay males are predatory, and that children need to stay away from them. Luke has internalized this fear, and makes an effort to be as appropriate and professional as possible around children. His noted fear of violence toward himself, or his congregants, from outsiders is quite alarming. Perceptions of possible violence may be an angle to explore in future research with queer identified people. I cannot elaborate here, as no other clergy felt threatened in this same way, and I do not have their stories to compare. However, this quote does lend a glimpse into the possible angles of discrimination coming from the larger culture in the U.S.

Many ministers sensed a great deal of homophobia throughout their lives, and for Amos that homophobia changed the way much of the relationships in his life would unfold. As mentioned previously, Amos was married for many years, and was out to his wife throughout their marriage.

I was in such despair about being able to live with a man. Being able to meet a man, to ever fall in love with a man, just seemed so impossible. I projected loneliness and isolation. I did tell her before we got married about my relationship with Bob, back in Berkeley. She was pretty much uninformed about homosexuality. I hardly more. Enough that she wasn't put off by that. We had a real joining of the souls, and just enjoyed each others' company. Both of us had a relatively positive place in life. Our friendship and relationship grew in other areas, but it was pretty much the same in terms of my clarity that I was gay. It was in seminary that I had reason to share with her that I had an experience with a guy. So we got a little counseling through a pastoral counselor at the seminary. 
So in that context I shared that I was struggling with homosexuality and so forth. This was pre-Stonewall. Most therapists were of the mind that it's a changeable aspect of life. That you can re-orient yourself. That was the approach of this particular pastoral counselor. The deepest part of me didn't buy that, but I had no experience to help me out of that. I pursued pastoral ministry, although when I entered seminary that wasn't my goal.

Reverend Amos went on to discuss how he felt that at the time he came out there was no possibility to maintain what he felt was a normal life, and be out and partnered at the same time. Being married to a woman, who he had a strong love for, was the best path he could see to living the kind of life he wanted to live. This desire to live life in a "normal" manner has been noted by several clergy. Many participants said this in different ways, including: "I don't want to be the gay preacher, I just want to live life like everyone else, I do not feel that I am any different as a person simply due to my sexuality" along with many other ways of stating a desire to not be singled out and stigmatized. The stigma was taken a step further for Amos, as he went to a counselor and attempted to "re-orient" himself to a straight identity prior to marriage.

This findings chapter was a space for the thoughts and voices of these queer identified clergy to be better discovered and heard. All of these narratives were candid and explore elements of the lives of clergy members that had not been divulged in previous research endeavors. I will now move on to a more descriptive discussion of what some of these stories indicate related to previous literature, theoretical concepts, and future research. 


\section{CHAPTER 5: Discussion}

In this chapter I discuss some of the key findings of this study, how they relate to my two main research questions, and how my literature and theoretical perspectives relate to interviewee's stories. The two research questions that motivated this study at the outset are:

1. What factors encourage or discourage queer identified clergy to pursue a career as professional religious leaders in a traditionally heteronormative occupation? (referred to throughout this document as entrance).

2. What factors encourage or discourage queer identified clergy to maintain their positions as professional religious leaders? (Referred to throughout this document as endurance)

This chapter is organized according to these two questions, and the two sections are segregated into sub-categories, which are organized to mirror the themes from the findings chapter. This is true, with the exception of themes that did not apply to the two research questions, but emerged from the data and help us to understand the experiences of queer clergy. At the end of each sub-section I will conclude with recommendations for future research that were generated by emergent themes in the data, as well as recommendations from clergy members throughout my interviews.

All of the themes (notated by each bold subheading) herein arose from narratives of clergy members' experiences, just as those in the findings chapter did, and are in no way fixed in these categories I have created. The organizational segments of this document are intended only to create clearly outlined statements, and in no way to delineate boundaries or values between themes. 
Research Question 1: Entrance

God's Calling

Participants in this study all concurred that their call to ordination came from a personal spiritual understanding that transcended any other element of their lives.

Theories of stigma and collective activity did not apply in the same way to this theme, as there was a unanimous statement that there is no choice but to become ordained. Queer identified people are stigmatized and subjected to certain treatment that others are not, but this did not stop anyone from recognizing a call from God to work for their church. "This advantage, gained from a refusal to accept the Church's teachings on homosexuality, does not spare them the pain of struggling to integrate spiritually with sexuality, but it does spare them years of time and agony" (Wilcox p67 2003). Several ministers did speak of a time when they were not out and the agony associated with that secrecy, but none of the people I interviewed allowed that agony to fully deter their ordination.

The "calling" theme for ordination was not foreseen prior to my interviews, as it was not part of the current scientific literature. The existing work in religious literature does not give any better explanation than the interviewees gave concerning their calling by God to ministry. A calling from god is difficult to connect to previous literature on identities and the stigmas attached to them, as the ontological outlook for people who sense a "call from God" precludes many influences and social norms outside their religious or spiritual beliefs (Berger 1990). This theme most closely relates to the way clergy identify as Christians first, and place their other identities second. Master status is 
a key concept here, as the majority of clergy felt that it was important to diminish all other identities and focus on being Christian. Placing more weight on this achieved master status helped many ministers enter the occupation, despite any possible discrimination they may have anticipated. This is similar to the way many of the teachers and police officers spoke of their drive to work in helping-professions despite the heternormative nature of the occupations. Both teachers and police officers reported a "natural calling" or urge to work with and help others, regardless of any bias they had encountered or anticipated. In this way, they too seem to have allowed their master statuses as educator or protector to overshadow other individual statuses and identities, in an effort to solidify a place in their new occupation.

What becomes clear is that one's master status plays a powerful role in clergy's entrance to heteronormative culture, overriding outside opposition to this master status. Furthermore, there exists a level of identity salience for this master status that is bolstered in a unique way, through a faith in belonging and calling to ministry that cannot be overtaken by perceived or experienced opposition to that status as minister. Throughout the interview process ministers in congregations that were open and affirming from their beginning often emphasized their identity and solidarity with queer individuals in their church. Clergy in more conservative and traditional faiths were more likely to emphasize their religious identity, relegating their sexual or gender identity as a secondary status. In this way, Stryker's theory holds true, that a person in any role will be more likely to solidify their place in that role if the majority of the people close to them are in the same culture, and hold the same values. By focusing on similar characteristics shared with 
other people in their faith, clergy members were able to gain and bolster a leadership position in their respective religious cultures. Several faiths were not approving or welcoming of gender or sexual minorities, and choosing one specific, their religious master status to identify more strongly with, instead of a gender or sexual minority status, was a crucial in entrance factor for queer clergy.

\section{Childhood and Youth Influences}

Denominations were chosen, for the majority of participants, by their parents when they were young. If parents were from two different denominations they often would select one to bring their children up in, commonly determined by the parent who went to church more or to whom church was most important. For most of the ministers I spoke with, the denomination chosen by their parents was not an open and affirming one, and for some it took years to switch to a faith that would ordain them. Three of these ministers were brought up in the Presbyterian faith, three Catholic, and others in various Christian traditions that do not ordain gender or sexual minorities. Although to differing degrees, each minister who grew up in a faith that was not open and affirming experienced some reluctance to change denominations and struggled with the internalized stigma from their childhood denomination.

For several of the ministers I interviewed, this need to change denominations was a tough decision that nearly kept them from pursuing their call. They mentioned pressure from their spiritual communities to change themselves, or leave the church they were in. This theme in the transcripts illuminates the possible magnitude of homophobic stigma on queer identified people, and some real negative consequences of that stigma. 
Homophobia is a separate theme that will be discussed in further detail in the following section.

Two participants stated that they came to understand their sexual identity through clergy members, as young adults. Both of these men mentioned envying the clergy who took charge of their church services. They later realized that they wanted to be like these prestigious men, and that they preferred the company of men and looked up to male peers specifically. This realization made them open to the possibility that they might be attracted to men, and eventually that they might be gay. This appears to be a unique succession of identity creation/realization, and certainly made a rich and interesting biographical piece for these two men. They both also felt that their experience was not as unique as it may sound, and that some non-open and affirming denominations could be filled with folks with their experience who chose not to come out to themselves, to others, or both. This concept that some people join faith traditions in an effort to hide their understanding of a minority sexual or gendered identity was mentioned in a number of interviews. One interviewee mentioned that he had strongly considered becoming ordained in the Catholic faith as a way to never need to come out, because he would be celibate for life in that case. Essentially, the stigma attached to queer identity, coupled with the tenets of his faith tradition, was strong enough to lead him to a life of secrecy and celibacy. Other participants spoke of hiding (or passing, as Goffman would have it) in different ways, for example being married and having children as a means of normalizing their identities and foregoing future attachment to stigma. Both of the two clergy members who had children in heterosexual marriages expressed some regret for 
their decision to hide their identity, but in no way regretted being in their families. One of these ministers repeatedly stated that there was no other way to live a normal life at the time he was ordained. He felt that in his conservative mid-western town there would never be a chance for him to experience what he felt was a healthy relationship with a man. All of these are major life changing decisions around which people attempted to normalize all of their related feeling and perceptions.

Literature on teachers, students, police officers, ministers, and rabbis has all pointed to this emphasis on negating sexual or gendered identities, and remaining silent about any behavior related to those identities as the sole solution to discrimination or prejudice. Striking similarities to the "Don't Ask Don't Tell (DADT)" policy of the United States Armed Forces are as obvious here as they are intentional (http://www.sldn.org/pages/about-dadt). The DADT makes silence an institutionally sanctioned policy, much in the same way many gender and sexual minorities face social sanctions from their earliest understanding of a sexual desire or identity.

\section{Seminary Experience}

Ministers included in the Women of the Cloth (1981) survey mentioned that their seminary experience was a very influential time in their path to ordination. Based on the WOC questions that touched on seminary, I asked each participant if they felt encouraged by peers and colleagues in their seminary to seek ordination. Several clergy members replied that it was necessary to be promoted by a current clergy member in order to be ordained. In some denominations, such as the Episcopalian faith, the only way to be 
accepted to a seminary school was through such promotion. These ministers all mentioned feeling very affirmed and encouraged throughout their experience, and received a great deal of support throughout seminary. This educational experience was a particularly important element of becoming ordained for many queer clergy, because for several participants it was the part of their path to ministry when they received the most affirmation from peers that they had previously feared and learned the most about their denominations.

After recognizing that they had been called to ministry, many ministers who were in open and affirming denominations found a great deal of encouragement from their peers and colleagues which enabled them to successfully continue on their path to ordination. This is one of several places that theories of collective identity apply to this research. As Stryker's theories of group cohesion point out, the closer people feel to others in their culture the more likely they are to maintain those positions within that culture (Stryker, 2000). These ministers mentioned a great deal of encouragement from other clergy members, family, friends, as well as fellow queer ministers from other faiths. The advent of women's ordination, along with the ordination of other queer identified clergy was noted throughout the interviews as an important source of encouragement for many ministers. Two ministers mentioned that gay rights issues like clergy ordination were built on the backs of women who had fought for civil rights in years prior.

All three Presbyterian ministers had some difficulty, with one of them nearly dropping out of the program prior to completion. For clergy who experienced difficulty in seminary, there were varying degrees of encouragement from peers, accompanied by a 
larger amount of discouragement and even blatant discrimination. The negative sentiments directed toward queer identified clergy members were based in ancient traditions and ideologies that remain in the seminaries of some faith traditions, and forced all of the people I worked with to change their denominational affiliation. Two of those ministers who were forced to switch denominations did so without much complication, and are now happier in their new position. One of those three former Presbyterians left her church and was disenchanted with Christianity in general for several years. The stigma and negativity placed on her identity caused her to stray from the religious identity that was causing discomfort. She has since entered a new faith tradition through an activist organization that is dedicated to helping queer Christians find the right place for themselves. Several lesbian Rabbis mentioned a similar discomfort and reluctance to continue with their religious endeavors upon realization that they needed to switch denominations. This is slightly more complicated for Rabbis than for Protestant clergy, as there are fewer open and affirming congregations within Judaism (Alpert et al).

For ministers who dealt with prejudice or discrimination in or outside their seminary experience there was a great push to become politically active and work toward change for the civil rights of gender and sexual minorities. This political motivation proved to be a source of encouragement and drive for them, and was noted by some as the element that most promoted them to pursue their clergy occupation.

Political Activism (Working Toward Change Inside or Outside the Church)

Despite acting as individuals in their separate denominations, all of the ministers I 
worked with announced some form of political activism that they felt brought them together with the greater struggle for civil rights. For several ministers, obtaining a clergy position was seen as an avenue to better create change inside and outside their church or faith tradition. Clergy members were linked to political activity in several different ways. Some were directly involved in the creation of activist networks and institutions, some identified more as teachers working to spread knowledge about positive aspects of religious culture, and still others found their activist outlet through spreading words of encouragement and fostering the unique relationships specifically or their congregation members. All of these ways of understanding action were focused around the betterment of social situations and institutions for other people, and particularly subjugated groups of Christians. Several ministers made the point that they did not want other Christians to have to endure the internalized homophobia and confusion that they had.

As Stryker and Serpe wrote, "Saying persons are connected to a group or social network is saying their relations to others depend on playing particular roles and having particular identities. Two analytically and empirically independent types of commitment exist: interactional, the number and frequency of relationships entered by playing a role; and affective, the depth of emotional attachment to particular sets of others" (Serpe 1987). Clergy members are part of a larger movement for equality and social justice, and the different movements associated with that ethos. The existence of that movement as something to be an active part of, the existence of subjugated groups of people who's rights can be fought for, and the prevalence of homophobic stigmas in mainstream culture are all factors that may keep these people stalwart in their roles as activists. Thus, all 
ministers are active in their congregations as teachers and helpers on an interactional level, and as role models to other queer Christians who may be unsure of how to navigate their identities. Furthermore, they all are deeply entrenched in the affective aspects of their congregants, as one minister noted: "It's a truly difficult and sometimes thankless job. We have to be deeply dedicated to our job and our congregation”. Both of Stryker's elements of group-identity place clergy members in the position as activists for the good of their fellow queer identified persons, as well as their fellow Christians. It is important to mention here that not all clergy members would be part of this social movement for equal rights if there was not a culture of change to belong to. Exemplifying Stryker's points about group involvement and commitment, several of the ministers I interviewed became activists and proponents of change only after they became clergy. This illustrates Stryker's point that people enter movements if other people who are close to them are in those social movements, or are highly supportive of those movements.

These ministers who entered social movements and organizations after ordination differ from the queer teachers in Rhoads' study, as many of those educators were part of activist cultures prior to becoming teachers (Rhoads 1994). Queer police officers, as mentioned in the literature review, had a similar experience to the ministers I worked with, finding activist elements and outlets through their new occupation. Many police officers found ways to work with the queer community in their city and on their beet as safe advocates and at times as mentors (Tobler 20060. People in all three occupations found avenues for positive change and activism within their chosen occupations, and many also considered themselves part of a movement for positive social change. This 
attachment of clergy roles to activist roles and sentiments is certainly an indispensable component of the entrance and endurance of those positions for many ministers.

Denominational Policies and Practices (Elements of faith traditions/denominations that have positive or negative influences)

When the stigma attached to clergy members is not being legitimated by other people in clergy positions or positions of power in their faiths, there is a lesser likelihood that it deterred a new clergy member from entering the occupation. People in traditionally open and affirming congregations experience far less stigma than those that began in denominations that exclude or prohibit gender or sexual minorities from positions such as pastoral ordination. In open and affirming denominations clergy members are not forced to be a token of any of their roles or identities, rather are allowed to be themselves and, as many of them noted, to "bring all of ourselves to church".

Being out and open within a church or occupation can also cause a clergy member to be tokenized, and used to exemplify their minority group within the church or workplace. Ministers in open and affirming denominations often stated that their church or denomination itself is a token within a larger context of faith an religious culture, and clergy in faiths where not every church is open and affirming spoke of being Goffman focused on tokenism in a broad sense when he wrote that "once a person with a particular stigma obtains a particular high occupational, political, or financial position how high depending on the stigmatized group in question - a new career is likely to be thrust upon him, that of representing his category. He finds himself too eminent to avoid 
being presented by his own as an instance of them. (This weakness of a stigma can thus be measured by how eminent a member of the category may be and yet manage to avoid those pressures)" (Goffman 1963 p26). By this understanding of stigma and tokenism it would appear that clergy members who convert from one faith tradition to another due to their stigmatized gender or sexual identity would be forced to be an example, or token, for other people who wish to do the same. Also, they could be seen as the exemplar for non-clergy in their denomination who are in search of a more accepting faith tradition. Three of the ministers I worked with mentioned a highly negative association to this sort of tokenism. They did not wish to be "the gay priest", or the one always expected to speak on behalf of gay rights and queer issues. None of them wanted to discuss sexuality or gender in all of their sermons, but felt that it was expected of them to do so. That is not to say that they did not identify in an activist sense as "the gay priest" who fought for equality, but that they preferred it not be all that they were thought of as. This was noted by all three of them, as well as several other ministers in more subtle ways, with statements like "I want to be known for more than being gay" and "people think they know what I will say about all gay issues. I don't like that. I want my chance to speak for myself'. This attachment of token status that some ministers expressed seemed to be harmful, as many of them noted that they would prefer not to be seen in such a way. They each mentioned that they would like to be treated the same as their straight colleagues, and not as people with one special element of themselves to offer.

Both of the Episcopalian ministers in this study mentioned that, due to the congregation level polity of their denomination, each church is very different regarding 
their level of acceptance and affirmation of gender and sexual minorities. A denomination having a congregation level polity means that a committee at each congregation makes decisions that shape the way that the congregation is run, what events are held, and how funds are allocated. Episcopalian ministers search for churches with the most liberal stance toward their identities, within the Episcopalian tradition, limited the scope of their search for possible geographical locations of employment. In contrast, for some faith traditions all tenets and regulations are passed down from a national or international body, and there is little space left for congregations to make decisions that will ultimately affect them. This focus on congregation level polity also greatly affected where ministers were able to look for jobs within their faith, as these denominations are often limited to liberal urban centers like Portland, Oregon or San Francisco, California. The three UCC ministers, three MCC ministers, one Unitarian Universalist minister, and one Gnostic minister would have no trouble obtaining an open position in most of their churches. That is not to say that they would not deal with stigma related to their identity from their previous denominations (as noted above), but that they would not face that stigma from their new denominational polity. This is because these denominations were created, at their very genesis, to be open and entirely affirming throughout all of their churches. The real challenge for clergy in these traditionally open and affirming traditions is that their churches are few and far between, positions do not often open up, and similar to the aforementioned Episcopalian ministers the majority of their churches are located in a few highly-liberal urban settings on the west and east coasts of the U.S. This is drastically different from the hiring and job search situation of queer teachers and police officers, 
both of whom worked in occupations that require hiring a more diverse group of employees. Religious organizations are not subject to the same hiring policies, as they are not funded by public tax dollars.

The only minister who was in a denomination that is neither open and affirming nor allowing ordination of queer identified clergy, was Joel who works at an American Methodist Church. As a slight outlier in this study, Joel came out to his congregation and denomination after he was ordained and employed, and is currently fighting to change the denomination's policies toward gendered and sexual minorities. Joel has consciously accepted a role as the token member of a queer subculture in the Methodist tradition and used it to work toward the good of others. Joel made the point that "there is no rule stating that I can't be here, and I will fight for what's right until they kick me out”. Joel has made it a life mission to deconstruct the walls of bias in the Methodist tradition and create a faith that is open and accepting of everyone who wishes to join.

As suggested by several participants, it would be advantageous to locate more people in Luke's position, and include ex-ministers as well as those who never made it to ordination, and create a study of queer identified clergy who are not in open and affirming congregations and are not interested in converting to those that are. During the first round of the interviews which focused on what I should be asking clergy members in my subsequent interviews, three ministers felt that it would be very interesting to study the reasons people did not make it all the way to ministry. They all felt that there were a far greater number of folks who attempted to become clergy and were not able to complete that quest for a variety of reasons than those who did. 


\section{Homophobia (Internal \& External)}

All but one of the ministers I spoke with mentioned experiencing internalized homophobia, and every one of them endured some level of homophobia from external sources. Each clergy members' childhood was filled with religious teachings, some of which helped to define and normalize heterosexual relationships, and demonize same sex relationships and alternative gender identities. Ministers also noted that gender roles are part of the teachings of many traditional religious institutions, and children are taught how women and men are "supposed to" interact and behave in a world that their faith traditions have deemed the right way to live. Internal homophobia is also known as sexual self stigma (Herek 2009). I am using the terms External and Internal Homophobia here to notate the origin of the homophobia being discussed. Internal homophobia comes from within the person, and is pointed at themselves as well as other sexual minorities. This form of homophobia stems from social forces outside of a minister's scope of control, and is internalized subconsciously (Herek 009. External homophobia refers to homophobia a person experiences that originates from another person's ideas or actions.

\footnotetext{
"Sexual self stigma, like sexual prejudice among heterosexuals, is an endorsement of a cultural ideology that disempowers sexual minorities, creates institutional barriers to their full participation in society, and fosters enactments of stigma against them (Herek, 2008). Currently, some institutions and ideologies in U.S. society (e.g., heterosexual masculinity, traditional Christianity, political conservatism) are characterized by especially high levels of heterosexism (e.g., Herek, 1986; Herek et al., 2007), and survey research has revealed higher levels of sexual prejudice among heterosexuals who are closely associated with those ideologies (i.e., men, the strongly religious, political conservatives) than among those who are not (women, the nonreligious, political moderates and liberals; e.g., Herek, 2009)" (Herek, Cogan, Gillis 2009).
}

This self stigma can have extensive negative psychological impacts on those who 
experience it. Here again, I was only able to work with people who overcame or found ways to deal with any self stigma (and most any external stigma for that matter) they may have experienced. That is to say that the people that I worked did experience self stigma, but (as noted previously) it would be useful to add the statements and stories of people who were not able to overcome or thwart internal or external homophobia.

There was not a single clergy member who did not experience some form and level of external homophobia, yet each individual dealt with it differently. The majority of participants placed themselves in cultures and situations where they felt most safe and capable of being out and affirmed in their identity. For three clergy members the timing they chose to come out to their faith communities was a problem, as it took place after they had already began seminary in denominations that do not ordain queer identified people. For these folks the best remedy to their new found stigmatization was to switch denominations (move to accepting environments). For two of them there was no problem with this transition. One minister left the church for quite some time, and struggled greatly with the idea of returning. This is likely the most indicative of Stryker's theories of stigma and identity, because all but one of the ministers I worked with was either raised in an open and affirming religious culture or moved to one prior to ordination. Ministers all wanted to be in places where their sexual or gendered identity was not a negative attribute of themselves, and this was presented by the majority of other participants having similar identities. There is not a great deal of sociological literature focused on this transition of space and culture due specifically to identity conflicts. I feel that this will be another good avenue for future research. The narratives of these three 
ministers could be compared with those who felt they had to forgo their call all together.

Lastly, all of the participants mentioned a sense of external homophobia from the larger culture, outside their faith traditions. Similar to the experience of teachers in Rhoads' study, several ministers said that they conduct themselves with extra caution around children. This cautionary behavior was a reaction to homophobic beliefs that queer persons are hypersexual, and may put children in danger of sexual abuse. This caution was not noted as a deterrent from entering or maintaining clergy positions, but was a constant reminder of the general societal disapproval of sexual and gender minorities. External homophobia from secular culture did not deter any of the participants from seeking ordination, rather it invigorated some to become a part of the movement for equality and civil rights. Nearly all interviewees mentioned a distancing from their secular acquaintances once they became clergy, stating that their secular friends felt judged or felt that ministers would not want to associate with them any longer. External homophobia was often manifest and recognized in negative comments about "choice" of sexuality, partner relationship, parenting abilities, perceived moral degradation, and endless other negative assumptions about who queer identified people are and what they do.

\section{Research Question 2: Endurance}

Only a quick skim of the previous pages in this document is required to notice that eleven of the twelve participants had predominantly positive experiences in their occupations after they were ordained, and have experienced few or no complications 
maintaining their position. Joel, the one minister who made the choice to stay in a nonopen and affirming denomination, is consciously trying to change its polity for the good of all its members. Joel's position is then maintained through hopes of positive change within that denomination. If that change does not come Joel is prepared to switch denominations, once excommunicated, and work for the good of fellow queer Christians in another capacity. Several other local clergy members have already been forced to make a similar transition, and Joel will have a full support network should the need arise.

As for positive aspects that are allowing clergy to maintain their positions, many of them mirror those listed above as reasons for initial entrance. When asked about encouraging elements of their jobs that make them want to stay in their positions participants listed reasons including: they are performing God's work, it is an avenue for involvement in the civil rights movement, it allows them to be role models for other queer Christians, enjoyment of working with the denomination level polity of their faith tradition, and working to thwart homophobia in Christianity and in the larger culture.

This question did not prove to be nearly as fruitful as the first, because a great deal of the answers were the same or highly analogous. The one factor that almost every respondent agreed was unique to their occupational endurance was an overarching sentiment of the positivity and perceived overall good of their religion or faith tradition. Every interview included some discussion of the essential good in religion, and the desire work for positive change in the world that was held by the majority of their congregants. This was stated, not as a reason to stay, but more a positive reminder of why participants had entered their occupation, and why they should endure the often hectic schedules and 
low monetary compensation.

Overall, asking clergy members what motivates them to remain in their positions helped to dislodge their stories of love and affection for their congregants. This experience is similar for all clergy, regardless of their gender or sexual identities, as the occupation is extremely demanding and requires that ministers truly enjoy it. As counselors and teachers, clergy grow very close to many of their congregants, and those relationships are an integral part of their occupation. This positive sentiment toward religion as an overall force for good was mentioned as a central factor of entrance and endurance by many participants. Similar sentiments come up in research literature on people in other helping professions, such as teachers and military personnel (Rhoads 1994). Many teachers mentioned that educating was important enough to them that they were willing to deal with the discomfort of the heterocentric culture of their career. It could be helpful to conduct a comparative study between these helping occupations, and look at how a sense of the overall good of an organization or institution is perceived by members, and what that good means to their involvement. Such a study might add to our understanding of how people attach meaning to their occupations, and how that meaning may be different from occupations with less personal emotional value attached to them. 


\section{CHAPTER 6: Future Research \& Conclusion}

Likely the most interesting and apropos extension of this study would be to add the stories of queer clergy who did not make it to the pulpit. Adding narratives of what factors lead perspective ministers to pursue other interests in their lives would help to illuminate the barriers to queer clergy's ordination. The obvious obstacle in such a study would be participant recruitment, as the population is very small and possibly somewhat reluctant to discuss their disjointed career path. Many of the ministers I interviewed felt that the number of people who give up or are forced out of the path to ordination is much greater than those who make it. It was suggested that I visit seminary schools to locate recent dropouts and people who are pursuing other paths of religious studies.

I would like to create an inquiry of the different things a call to ministry means to each clergy member, why they feel this call comes to them rather than others, how they understood what to do with the call, and any other avenues that clergy may feel pertinent to their experience of a call. Several of the clergy members I worked with mentioned that I should be asking them if they felt that being queer had anything to do with their call (i.e. were they called specifically because of their sexual or gendered identity). Unfortunately this indicator only came up in later interviews and could not be added to the study, as it could not be compared to the half that existed prior.

Additionally, I would like to suggest some future methodological additions to this research that could make it a much larger and more descriptive piece of literature. First, adding questions that focus on the origin of phobias and biases could allow for opportunity to test several theories that I was not able to use with my former question set. 
These would include a variety of pieces from queer theory that focus on the ways individuals understand their sexuality, the ways that meanings of sexuality differ for individuals, and where those meanings and understandings differ from how individuals are perceived by the larger groups they belong to. Most frequently used in discourse analysis, these theories have had little use thus far in sociology, and I am confident that their place in the field will be a useful and progressive one. The few articles written on Queer Theory and Sociology, most notably those by Ben Agger, have outlined a place in sociology for such philosophies, now it is time to put them into practice.

In further addition to this project I would like to interview clergy members in several other cities across North America, and possibly international locations of the same denominations, with the intention of creating a more transferable understanding of the analytical and theoretical findings. This will require a set of preliminary interviews to assess the best location to extend the study to. Some previously suggested cities include Seattle, Washington, San Francisco, California, Madison, Wisconsin, Richmond, Virginia, among others. It is important to locate some queer identified clergy members who do not live in these "liberal pocket" locations, and may experience different types or levels of bias and discrimination surrounding their ordination. In order to locate all these folks an extensive snowball sample will be necessary, including any and all organizations that work with open and affirming denominations. One such organization generated approximately fifteen contacts for my last research piece, and I hope that similar results will come from several others in different geographical areas.

Lastly, I would like to add a focus group component to this research that might 
allow clergy to share and compare (Morgan, D.) their experiences with one another. The focus group would only be plausible in urban centers with two or more queer identified clergy members present to work with. Through this process of comparison, clergy will have the opportunity to address issues and remind one another of things that may not otherwise arise in one on one interviews. Some of the issues clergy members brought forth in my previous research were not present in the literature or theory that I had used to create the interview instrument. This addition will further allow me to learn more about what should be addressed in the in-depth interviews. Comparing interviews and focus groups side by side may allow me to discuss the strengths and drawbacks of either method for working with a sensitive topic, and sub-cultural population.

These additions will create a more rich and descriptive account of the issues clergy face and the possible origins of those issues. The analysis of such data will give those in charge of congregations and denominations a better look at the people who serve their worship services and institutions, and will hopefully create a better atmosphere for everyone involved. 


\section{CONCLUSION}

To simplify with an umbrella statement of the most important findings of this research project I would summate with the following: a "Calling from God" is the ubiquitous determination factor for all clergy to become ministers (although they all had additional reasons), master statuses are established in an effort to thwart homophobia and discrimination within a clergy member's religious culture. And although queer ministers have endured some extreme hardships throughout their path to ordination, many religious institutions are becoming more accepting of persons of all minority identities.

The calling from God was the most discernible impetus for entrance into the ministry for all participants in this study. Latching on to this call made it possible for ministers to negate or overlook the homophobic overtones or remnants of their faith traditions and focus on their master status of clergy, becoming involved in civil rights or gay rights activism, as well as other avenues for social change.

To close, I would like to highlight the positive shift in Protestant denominations that has enabled many of the people I worked with here to obtain their positions. Denominations like the Metropolitan Community church have been created with the sole purpose of creating space for minorities who do not feel welcome in other churches. Moreover, denominations that have been around for hundreds of years, like the Episcopalian Church, are becoming open and affirming institutions and are ordaining sexual and gender minorities intentionally. This positive shift toward essentialist acceptance in some faith traditions has also assigned other faith traditions the task of discussing queer ordination, and forced many of them to openly take a stance on this 
issue that may have been dormant for centuries. 


\section{Appendix A (Participant Demographics)}

\begin{tabular}{|c|c|c|c|c|c|}
\hline Pseudonym & Denomination & Age & Race & Years Ordained & $\begin{array}{l}\text { Gender Identity (GI) } \\
\text { Sexual Identity (SI) }\end{array}$ \\
\hline Rebecca & $\begin{array}{l}\text { United Church } \\
\text { of Christ }\end{array}$ & 58 & White & 11 & $\begin{array}{l}\text { GI: Female } \\
\text { SI: Lesbian }\end{array}$ \\
\hline Samuel & $\begin{array}{l}\text { Metropolitan } \\
\text { Church of } \\
\text { Christ }\end{array}$ & 57 & White & $\mathrm{n} / \mathrm{a}$ & $\begin{array}{l}\text { GI: Male } \\
\text { SI: Gay }\end{array}$ \\
\hline Joshua & $\begin{array}{l}\text { United Church } \\
\text { of Christ }\end{array}$ & 45 & White & $\mathrm{n} / \mathrm{a}$ & $\begin{array}{l}\text { GI: Male } \\
\text { SI: Gay }\end{array}$ \\
\hline Joel & & 58 & White & 27 & $\begin{array}{l}\text { GI: Transgendered } \\
\text { SI: n/a }\end{array}$ \\
\hline Gabriel & $\begin{array}{l}\text { Metropolitan } \\
\text { Church of } \\
\text { Christ }\end{array}$ & 47 & White & 5 & $\begin{array}{l}\text { GI: Male } \\
\text { SI: Gay }\end{array}$ \\
\hline Mary & $\begin{array}{l}\text { Metropolitan } \\
\text { Church of } \\
\text { Christ/Wicca }\end{array}$ & 55 & White & $\mathrm{n} / \mathrm{a}$ & $\begin{array}{l}\text { GI: Female } \\
\text { (Formerly } \\
\text { Transgendered) } \\
\text { SI: Lesbian }\end{array}$ \\
\hline Ezra & $\begin{array}{l}\text { United Church } \\
\text { of Christ }\end{array}$ & $\mathrm{n} / \mathrm{a}$ & White & $\mathrm{n} / \mathrm{a}$ & $\begin{array}{l}\text { GI: Female } \\
\text { SI: Lesbian }\end{array}$ \\
\hline Amos & $\begin{array}{l}\text { Church of the } \\
\text { Brethren }\end{array}$ & $\begin{array}{l}\text { Mid } \\
60 \mathrm{~s}\end{array}$ & White & $\mathrm{n} / \mathrm{a}$ & $\begin{array}{l}\text { GI: Male } \\
\text { SI: Gay }\end{array}$ \\
\hline Jude & Gnostic & 56 & White & $\mathrm{n} / \mathrm{a}$ & $\begin{array}{l}\text { GI: Male } \\
\text { SI: Gay }\end{array}$ \\
\hline Ruth & Episcopalian & 67 & White & $\mathrm{n} / \mathrm{a}$ & $\begin{array}{l}\text { GI: Female } \\
\text { SI: Lesbian }\end{array}$ \\
\hline Luke & $\begin{array}{l}\text { Unitarian } \\
\text { Universalist }\end{array}$ & 47 & White & 15 & $\begin{array}{l}\text { GI: Male } \\
\text { SI: Gay }\end{array}$ \\
\hline Titus & Episcopalian & $\mathrm{n} / \mathrm{a}$ & White & $\mathrm{n} / \mathrm{a}$ & $\begin{array}{l}\text { GI: Male } \\
\text { SI: Gay }\end{array}$ \\
\hline
\end{tabular}

*n/a (not available) is used here to notate demographics that were not answered. 


\section{Appendix B (Interview Guide)}

1. Demographics:

- age

- number of years as clergy

- past and present denomination(s)

- race

- gender and sexual identity

2. Please tell me all about your initial call to ministry.

- Was this linked to your childhood denomination?

- At what point in your life did you feel that this was the path for you?

- Were you out to anyone when you decided to pursue your call?

3. Can you share a little bit about you seminary experience?

- How did you select the school?

- Did this education affect your decision to become ordained? (How so?)

- Were you encouraged (or discouraged) to pursue ordination by your classmates and teachers in seminary?

- Was your seminary school affiliated with the denomination you work with now? (if not, why?)

4. Why did you choose the denomination you are currently employed with?

- Is it the same denomination you attended as a child?

- Was the decision to seek employment at this denomination based on anything other than its spiritual tenets or teachings?

5. Did you come out before or after ordination?

- In what order did the process of coming out happen for you? Were you out to yourself first, to people other than the church you worked at?

- Why did you come out when you did, and not at some other time?

- Did coming out affect you position or path to ordained clergy?

- How has coming out effected other aspects of your life?

- What is unique to your faith tradition that allows you to be out?

6. Can you tell me about any homophobia you have dealt with or are dealing with throughout your life?

- Have you ever encountered internal homophobia? (follow with an explanation if necessary)

- Have you encountered homophobia from your denomination, congregation, peers or colleagues?

- Are you allowed to be partnered in you faith tradition? 


\section{Consent Letter}

\section{Pulpit at the End of the Rainbow: A Qualitative Study of Queer Identified Persons Entering Heteronormative Space.}

You are invited to participate in a research study conducted by Brian Gregory Gerow from experience of queer identified persons as they enter clergy positions, and will attempt to describe any difficulties or achievements of that experience. Brian Gerow is a graduate student at PSU and this study is conducted as a graduation requirement for a master's degree. The study will be conducted under that supervision of Dr. Lindsey Wilkinson, a faculty member of the Sociology Department at PSU.

If you decide to partake, you will be asked to participate in an audio-recorded interview with Brian Gerow. These interviews will be conducted once, in-person, and will last approximately 45-60 minutes. If it is not possible for you to meet with Brian at a location of your choice, the interviews may also be conducted over the telephone. While participating in this study, it is possible that topics may come up that are emotionally sensitive or may cause emotional discomfort. If at any time you feel uncomfortable, or wish to end the interview, you can simply inform Brian, and the interview will cease. You may not receive any direct benefit from taking part in this study, but the study may help to increase knowledge which may help others in the future.

Any information that is obtained in connection with this study and that can be linked to you or identify you will be kept confidential. Subject identities will be kept confidential, and you will be given the opportunity to pick a pseudonym for yourself before the interview begins. Finally, Brian will make a copy of the transcript available to you after the interview if you should request one.

Your participation is voluntary. You do not have to take part in this study, and it will not affect your relationship with either Brian or PSU. You may also withdraw from this study at any time without recrimination.

If you have concerns or problems about your participation in this study or your rights as a research subject, please contact the Human Subjects Research Review Committee, Office of Research and Sponsored Projects, 600 Unitus Bldg., Portland State University, (503) 725-4288 / 1-877-480-4400. If you have questions about the study itself, contact Brian Gerow at: Department of Sociology P.O. Box 751 Portland, OR 97207-0751. You may also contact Brian via telephone at 541-520-8140.

Your signature indicates that you have read and understand the above information and agree to take part in this study. Please understand that you may withdraw your consent at any time without penalty, and that, by signing, you are not waiving any legal claims, rights or remedies. The researcher will provide you with a copy of this form for your own records. 


\section{BIBLIOGRAPHY}

Adam, Barry D. 1995. The Rise of a Gay and Lesbian Movement. Twayne Publishers.

Alpert, Rebecca T. Sue Levi Elwell. Shirley Idelson. 2001. Lesbian Rabbis: The First Generation. Rutgers State University.

Berger, Peter. 1990. The sacred canopy: Elements of a Sociological Theory of Religion. Anchor Press

Boswell, John. 1980. Christianity, Social Tolerance, and Hmosexuality: Gay People in Western Europe from the Beginning of the Christian Era to the Fourteenth Century. University of Chicago Press, Ltd. London

Bunzl, Matti.1997. Outing as Performance / Outing as Resistance: A queer Reading of Austrian (Homo) Sexualities. Cultural Anthropology 12(1): 129-151. American Anthropological Society

Butler, Judith (1999) [1990]. Gender Trouble: Feminism and the Subversion of Identity. New York: Routledge.

Callero, Peter. 1985. Role-Identity Salience. Social Psychology Quarterly, Vol. 48, No. 3 (Sep., 1985), pp. 203-215

1986. Toward a Meadian Conceptualization of Role. The Sociological Quarterly, Vol. 27, No. 3 (Autumn, 1986), pp. 343-358. Blackwell Publishing on behalf of the Midwest Sociological Society.

Carroll, Jackson W., Barbara Hargrove, Adair T. Lummis. 1983. Women of the Cloth: A New Opportunity for the Churches.

Charmaz, Kathy. 2006. Constructing Grounded Theory: A Practical Guide through Qualitative Analysis. Sage. London.

Collier, Peter J. Peter Callero. 2005. Role Theory and Social Cognition: Learning to Think Like a Recycler. Self and Identity, 4: 45-58,Copyright \# 2005 Psychology Press ISSN: 1529-8868

D'Emilio, John. Estelle B. Freedman. 1988. Intimate Matters: A History of Sexuality in America. Chicago University Press

Durkheim, Emile. 1912, The Elementary Forms of Religious Life (Oxford World's Classics): Translated by Carol Cosman. ISBN 0199540128 
Edsall, Nicholas C. 2003. Toward Stonewall: Homosexuality and Society in the Modern Western World. University of Virginia Press.

Foucault, Michel. 1976. The History of Sexuality Vol. 1: The Will to Knowledge. London: Penguin

Glaser, Barney G. September 2002. Constructivist Grounded Theory. Forum: Qualitative Social Research. Volume 3, No. 3, Art. 12

Goffman, Erving. 1983. Stigma: Notes on the Management of Spoiled Identity. Simon \& Schuster. New York, New York.

Hazel, Dann. 2000. Witness: Gay and Lesbian Clergy Report from the Front. Weseminster John Knox Press.

Hanis-Martin, Jennifer L. 2006. Embodying Contradictions: The Case of Professional Women's Basketball. Journal of Sport and Social Issues. 30;265

Herek, 1998. Stigma and Sexual Orientation: Understanding Prejudice Against Lesbians, Gay Men, and Bisexuals. Sage Publications. Thousand Oaks, California

Herek, Cogan, Gillis. 2009. Internalized Stigma among Sexual Minority Adults: Insights From a Social Psychological Perspective. Journal of Counseling Psychology. Vol 56. No1. 32-43

Linneman, Thomas J. 2003. Weathering Change: Gay and Lesbian, Change, Christian Conservatives, and Everyday Hostilities. New York University Press

Lehman, Edward C. Jr. 1985. Women Clergy: Breaking through Gender Barriers. Transaction Books. New Brunswick, New Jersey 08903

Leviticus 18:22 The King James Version of the Bible, originally published in 1611

Lowe, Mary Elise. 2009. Gay, Lesbian, and Queer Theologies: Origins, Contributions, and Challenges. Wiley Periodicals and Dialogue, Inc.

McQueeney, Krista. 2009. “We're God's Children Y'all:” Race, Gender, and Sexuality in Lesbian and Gay-Affirming Congregations. Social Problems, vol 56, issue 1. pp, 151-173

Quinlivan, Town. 1999. “Queer Pedagogy, educational practice and lesbian and gay youth”. Qualitative Studies in Education. VOL. 12, NO. 5, 509 \pm 524 
Rasmusen, Mary Lou. 2004. The Problem of Coming Out. Theory Into Practice: Sexual Identities and Schooling. Spring. pp. 144-150

Rhoads, Robert A. 1994. Coming Out in College: The Struggle for a Queer Identity. Bergin \& Garvey. Westport CT.

Roden, Fredrick S. 2001. Queer Christian: The Catholic Homosexual Apologia and Lesbian Gay Practice. International Journal of Gender and Sexuality Studies. Vol 6 No. 4. October.

Stryker, Sheldon (et al) 2000. Identity Competition: Key to differential Social Movement Participation?. University of Minnesota Press.

Serpe, Richard T. 1987. "Stability and Change in Self: A Structural Symbolic Interactionist Explanation. Social Psychology Quarterly. 50:44-55

Tobler, Aaron. 2006. "We do General Policing”: Sexuality in the Gay and Lesbian Liaison Unit of the Metropolitan Police Department, Washington, D.C. Graduate Journal of Social Science. Volume 3, Issue 2.

Wilcox, Melissa M. 2003. Coming Out in Christianity: Religion, Identity, \& Community. Indiana University Press. Bloomington \& Indiana

Zikmund, Barbara B, Adair T Lummis. Patricia Mei Yin Chang. 1998. Clergy Women, an Uphill Calling. Westminster John Knox Press. Louisville, KY.

\section{Website References}

http://www.nhepiscopal.org/

http://www.nytimes.com/2010/03/18/us/18bishop.html?ref=v gene robinson

http://www.polity.co.uk/giddens5/students/glossary/m-r.asp (definition of Group Identity \& salience)

http://www.queertheory.com/politics/coming out.htm (definition of "coming out")

http://www.sldn.org/pages/about-dadt

http://ufmcc.com/overview/history-of-mcc/

http://www.welcomingcongregations.org/joincwc.html. 